Original Article

\title{
Assessment of Mental Workload and Job Burnout of Medical Employees during the COVID-19 Pandemic in Iran
}

\author{
Ghazale Sadeghzade $^{1}(\mathbb{D})$, Somaye Rahmati ${ }^{1}$, Fatemeh Sadeghi ${ }^{1}(D$, \\ Amjad Mohammadi Bolbanabad ${ }^{2}$, Ebrahim Darvishi ${ }^{*}$ (iD
}

1. MSc Student, Faculty of Humanities, Kurdistan University, Sanandaj, Iran

2. Research Assistant Professor, Social Determinants of Health Research Center, Research Institute for Health Development, Kurdistan University of Medical Sciences, Sanandaj, Iran

3. Assistant Professor, Department of Occupational Health Engineering, School of Health, Kurdistan University of Medical Sciences, Sanandaj, Iran

Article Info $\quad$ ABSTRACT

Received: 2021/05/23;

Accepted: 2021/08/28;

ePublished: 2021/09/21

$\underline{10.30699 / j e r g o n .9 .2 .1}$

Use your device to scan and read the article online

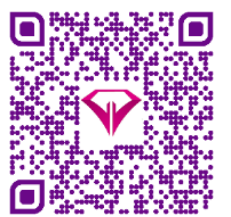

\section{Corresponding Author}

Ebrahim Darvishi

Assistant Professor, Department of Occupational Health Engineering, School of Health, Kurdistan

University of Medical

Sciences, Sanandaj, Iran

Email:

darvishi.hse@gmail.com
Background and Objectives: The pandemic and the crisis caused by the COVID-19 have challenged health care organizations around the world, causing human casualties and health concerns around the world and in Iran. The purpose of this study was to evaluate the mental workload and job burnout of medical employees during the Covid-19 pandemic in Iran.

Methods: The present descriptive-analytic research has been conducted on 510 medical and diagnostic staff in Tehran, Isfahan, and Sanandaj. The mental workload and the job burnout of staff have been evaluated using NASA-TLX software and the job burnout Maslach, respectively. Statistical tests including t-test, ANOVA, and multivariate linear regression were used to analyze the data using a STATA-14 software package.

Results: The mean mental workload of employees associated with patients suffering COVID-19 and those not associated was estimated at $83.7 \pm 8.1$ and $79.9 \pm 9.6$, respectively. The mean of job burnout was estimated at $79.6 \pm 16.2$ and $79.7 \pm 16.9$, respectively, which were not statistically significant. The results of linear regression showed that being married (coefficient $=-6.57, P=0.003$ ), employment as a Tarh (coefficient $=-12.71, P=0.002$ ), inverse relationship and Work in Isfahan hospitals (coefficient $=21.21, P<0.001$ ) was directly related to burnout. Women (coefficient $=3.61, P<0.001$ ), having a relationship with COVID-19 patients (coefficient $=5.9, P<0.001$ ) had a direct relationship with the amount of mental work.

Conclusion: The mental workload and job burnout in medical employees during the COVID-19 pandemic are high, and warning and the mental workload in employees associated with patients suffering COVID-19 are higher than other employees.

Keywords: COVID-19, Mental workload, Job burnout, Medical staff

\section{How to Cite This Article:}

Sadeghzade G, Rahmati S, Sadeghi F, Mohammadi Bolbanabad A, Darvishi E. Assessment of Mental Workload and Job Burnout of Medical Employees during the COVID-19 Pandemic in Iran. Iran J Ergon. 2021; 9(2):1-16 


\section{Extended Abstract}

\section{Introduction}

The pandemic and the crisis caused by the COVID-19 have challenged health care organizations around the world, causing human casualties and health concerns around the world and in Iran. In the meantime, medical staff, especially physicians and nurses, will be exposed to mental stress and burnout due to direct contact with Covid19 patients, risk of infection, and a high volume of patients. The purpose of this study was to evaluate the mental workload and job burnout of medical employees during the Covid-19 pandemic in Iran.

\section{Methods}

The present descriptive-analytic research has been conducted on 510 medical and diagnostic staff in Tehran, Isfahan, and Sanandaj. The employees' demographic information included age, sex, marital status, work experience, type of work shift, and direct relationship with COVID-19 patients or no relationship, was collected using a questionary. Moreover, the mental workload and the job burnout of staff have been evaluated using NASA-TLX software and the Maslach Burnout Inventory (MBI), respectively. The NASA task load index (NASA TLX) is a tool for measuring and conducting a subjective mental workload (MWL) assessment. It includes six subjective subscales: Mental, Physical and Temporal demands of the task, Performance, Effort, and Frustration. MBI is a psychological assessment instrument comprising 22 symptom items pertaining to occupational burnout. The MBI measures three dimensions of burnout: emotional exhaustion, depersonalization, and personal accomplishment. Finally, statistical tests including t-test, ANOVA, and multivariate linear regression were used to analyze the data using a STATA-14 software package.

\section{Results}

The mean age and work experience of the employees were $29.28 \pm 54.87$ and $11.2 \pm 3.7$. All employees were shift workers. About 67.1\% (342 people) of employees were women, and $64.2 \%$ (327 people) were married, and $67.1 \%$ of them worked in the COVID-19 wards. The mean mental workload of employees associated with patients suffering COVID-19 and those who were not associated was estimated at $83.7 \pm 8.1$ and $79.9 \pm 9.6$, respectively. The mean of job burnout was estimated at $79.6 \pm 16.2$ and $79.7 \pm 16.9$, respectively, which were not statistically significant.

Figure 1 shows the total values of mental workload and burnout of employees along with the subscales. The mean $( \pm \mathrm{SD})$ of mental workload and burnout of staff according to demographic variables are shown in Table 1.

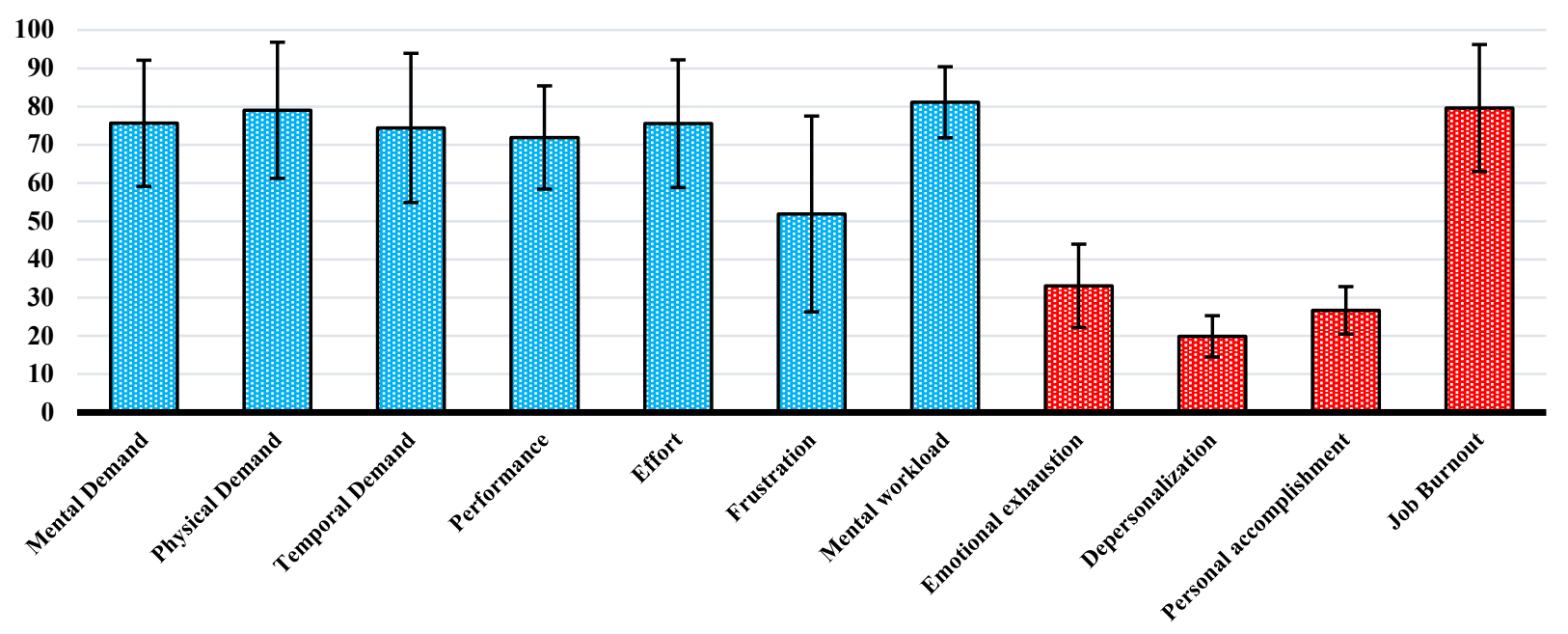

Figure 1. Mean mental workload and burnout of employees along with subscales 
Ghazale Sadeghzade et al.,

Table 1. Mean (SD) of Mental workload and Job burnout by the demographic variables of respondents

\begin{tabular}{|c|c|c|c|c|c|}
\hline Variable & Number (\%) & $\begin{array}{c}\text { Mental workload } \\
\text { Mean (SD*) }\end{array}$ & P-value & $\begin{array}{l}\text { Job burnout } \\
\text { Mean (SD) }\end{array}$ & P-value \\
\hline \multicolumn{6}{|l|}{ Sex } \\
\hline Male & $168(32.9)$ & $79.4(10.5)$ & $0.004^{* *}$ & $80.8(18.3)$ & $0.271^{* *}$ \\
\hline female & $342(67.1)$ & $81.9(8.5)$ & & $79.1(15.7)$ & \\
\hline \multicolumn{6}{|c|}{ Marital status } \\
\hline Single & $182(35.8)$ & $79.7(8.6)$ & $0.016^{* *}$ & $83.7(14.2)$ & $0.001^{* *}$ \\
\hline Married & $327(64.2)$ & $81.8(9.6)$ & & $77.4(17.4)$ & \\
\hline \multicolumn{6}{|l|}{ Age Group } \\
\hline$\leq 25$ & $139(27.6)$ & $78.9(10.4)$ & & $78.6(14.8)$ & \\
\hline $25-35$ & $297(58.9)$ & $82.0(8.6)$ & $0.004^{* * *}$ & $81.4(17.1)$ & $0.002^{* * *}$ \\
\hline$\geq 35$ & $68(13.5)$ & $80.9(8.2)$ & & $73.9(16.2)$ & \\
\hline \multicolumn{6}{|c|}{ Work experience } \\
\hline$\leq 5$ & $314(67.1)$ & $80.5(9.1)$ & & $80.4(16.1)$ & \\
\hline $5-10$ & $85(18.2)$ & $82.8(10.8)$ & $0.108^{* * *}$ & $85.7(17.5)$ & $0.001^{* * *}$ \\
\hline$\geq 10$ & $69(14.7)$ & $80.6(7.8)$ & & $72.4(16.7)$ & \\
\hline \multicolumn{6}{|c|}{ Type of employment } \\
\hline Rasmi & $20(4.0)$ & $86.8(8.6)$ & & $82.0(12.3)$ & \\
\hline Peymani & $231(45.7)$ & $80.7(9.5)$ & $0.019^{* * *}$ & $82.3(17.7)$ & $0.001^{* * *}$ \\
\hline Tarhi & $255(50.4)$ & $81.2(9.1)$ & & $76.7(15.1)$ & \\
\hline \multicolumn{6}{|l|}{ BMI } \\
\hline$\leq 25$ & $145(33.4)$ & $80.4(6.9)$ & & $88.9(14.5)$ & \\
\hline $25-30$ & $231(53.2)$ & $80.6(10.7)$ & $0.003^{* * *}$ & $76.3(16.1)$ & $0.001^{* * *}$ \\
\hline$\geq \mathbf{3 0}$ & $58(13.4)$ & $85.1(6.8)$ & & $70.1(12.8)$ & \\
\hline \multicolumn{6}{|c|}{ Work in COVID-19 ward } \\
\hline Yes & $348(68.2)$ & $79.9(9.6)$ & $0.001^{* *}$ & $79.7(16.8)$ & $0.931^{* *}$ \\
\hline No & $142(31.8)$ & $83.7(8.1)$ & & $79.6(16.2)$ & \\
\hline \multicolumn{6}{|l|}{ City } \\
\hline Kurdistan & $180(35.3)$ & $82.1(9.1)$ & & $70.9(12.7)$ & \\
\hline Esfahan & $231(46.3)$ & $79.5(9.3)$ & $0.001^{* * *}$ & $87.3(16.4)$ & $0.001^{* * *}$ \\
\hline Tehran & $94(18.4)$ & $83.2(8.9)$ & & $77.4(14.5)$ & \\
\hline Total & 510 & $81.1(9.3)$ & - & $79.6(16.6)$ & - \\
\hline
\end{tabular}

Also, the dimensions of mental workload and job burnout of employees with and without communication with COVID-19 patients are analyzed in Table 2. 
Table 2. Subscales of mental workload and job burnout of employees with and without communication with COVID-19 patients

\begin{tabular}{|c|c|c|c|c|c|}
\hline \multirow[t]{2}{*}{ Variables } & \multicolumn{2}{|c|}{$\begin{array}{c}\text { Relationship with COVID-19 } \\
\text { patients }(\mathrm{N}=348)\end{array}$} & \multicolumn{2}{|c|}{$\begin{array}{l}\text { Relationship without COVID- } \\
19 \text { patients }(\mathrm{N}=142)\end{array}$} & \multirow[t]{2}{*}{ P-value } \\
\hline & Mean & SD & Mean & SD & \\
\hline \multicolumn{6}{|l|}{ Mental Workload } \\
\hline Mental demand & 78.5 & 17.2 & 74.2 & 16 & 0.006 \\
\hline Physical demand & 81.9 & 19.8 & 77.6 & 16.7 & 0.011 \\
\hline Temporal demand & 76.1 & 21.7 & 73.5 & 18.3 & 0.165 \\
\hline Performance level & 71.4 & 12.2 & 72.2 & 14.1 & 0.507 \\
\hline Effort level & 80.1 & 16.5 & 73.4 & 16.4 & 0.001 \\
\hline Frustration & 50.5 & 28.6 & 52.6 & 24.1 & 0.394 \\
\hline Total score & 83.7 & 8.1 & 79.9 & 9.6 & 0.001 \\
\hline \multicolumn{6}{|l|}{ Job burnout } \\
\hline Emotional exhaustion & 33.9 & 10.1 & 32.6 & 10 & 0.16 \\
\hline Depersonalization & 18.5 & 4.1 & 20.6 & 5.7 & 0.001 \\
\hline Personal Accomplishment & 27.1 & 5.1 & 26.5 & 6.6 & 0.309 \\
\hline Total score & 79.6 & 16.2 & 79.7 & 16.8 & 0.931 \\
\hline
\end{tabular}

The variables in Table1, which had a significant relationship with job burnout, were entered into the regression model as covariates. The model with the highest R2 was determined ( $2=0.29)$. Married status (coefficient $=-6.57,95 \% \mathrm{CI}:-10.85,-2.29$ ), tarhi employment (coefficient $=-12.71,95 \% \mathrm{CI}$ : $20.56,-4.84)$ were negatively correlated with the job burnout. But, work at hospitals of Esfahan (coefficient $=12.21,95 \%$ CI: 7.83, 16.57) was positively correlated with job burnout (Table 3 ).

Table 3. Regression model for predicting job burnout in employees

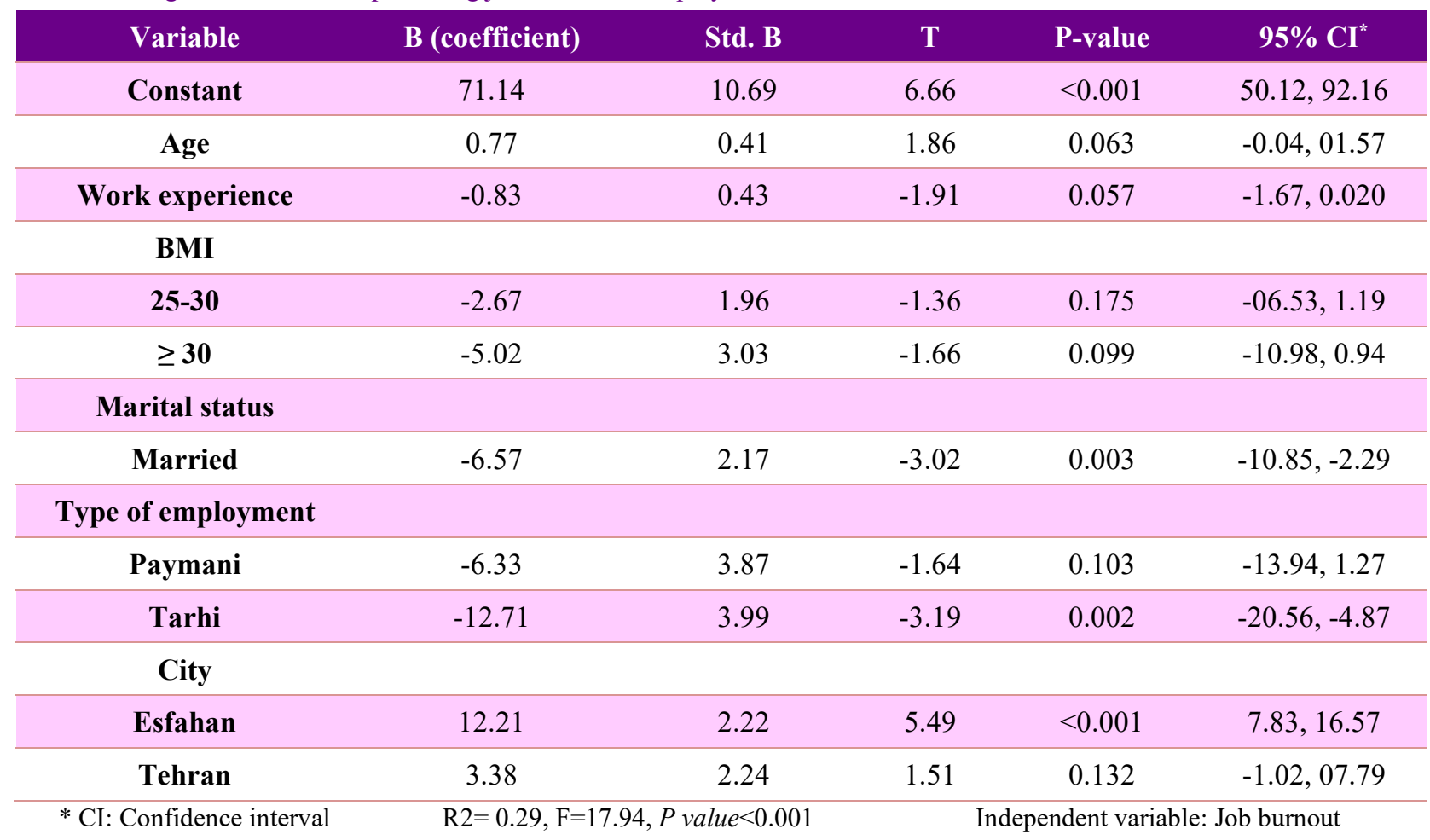


The variables in Table 1 which had a significant relationship with the mental workload were entered into the regression model as covariates. The model with the highest $\mathrm{R} 2$ was determined $(\mathrm{R} 2=0.16)$. Being female (coefficient $=3.61,95 \%$ CI: 1.84 , 5.36), don't work in COVID-19 ward (coefficient=
5.90, 95\% CI: 3.93, 7.88), and work at hospitals of Tehran (coefficient $=2.72,95 \%$ CI: $0.17,5.27$ ) were positively correlated with the mental workload. But, work at hospitals of Esfahan (coefficient $=-2.68,95 \%$ CI: $-5.32,-0.04)$ was negatively correlated with job burnout (Table 4).

Table 4. Regression model for predicting mental workload in employees

\begin{tabular}{|c|c|c|c|c|c|}
\hline Variable & B (coefficient) & Std.B & $\mathrm{T}$ & P-value & $95 \% \mathrm{CI}^{*}$ \\
\hline Constant & 77.40 & 3.73 & 20.76 & $<0.001$ & $70.07,84.72$ \\
\hline Age & 0.02 & 0.08 & 0.28 & 0.777 & $-0.15,0.19$ \\
\hline \multicolumn{6}{|l|}{ Sex } \\
\hline Female & 3.61 & 0.89 & 4.03 & $<0.001$ & $1.84,5.36$ \\
\hline \multicolumn{6}{|l|}{ BMI } \\
\hline $25-30$ & -2.16 & 1.15 & -1.88 & 0.061 & $-4.43,0.09$ \\
\hline$\geq 35$ & -0.36 & 1.77 & -0.21 & 0.837 & $-3.86,3.13$ \\
\hline \multicolumn{6}{|c|}{ Marital status } \\
\hline Married & 2.31 & 1.27 & 1.82 & 0.070 & $-0.19,4.81$ \\
\hline \multicolumn{6}{|c|}{ Type of employment } \\
\hline Peymani & 0.06 & 2.31 & 0.03 & 0.977 & $-4.47,4.60$ \\
\hline Tarhi & -1.17 & 2.41 & -0.48 & 0.628 & $-5.91,3.57$ \\
\hline \multicolumn{6}{|c|}{ Work in COVID-19 ward } \\
\hline No & 5.90 & 1.00 & 5.88 & $<0.001$ & $3.93,7.88$ \\
\hline \multicolumn{6}{|l|}{ City } \\
\hline Esfahan & -2.68 & 1.34 & -2.00 & 0.046 & $-5.32,-0.04$ \\
\hline Tehran & 2.72 & 1.29 & 2.10 & 0.036 & $0.17,5.27$ \\
\hline
\end{tabular}

* CI: Confidence interval

Independent variable: mental workload

$\mathrm{R} 2=0.16, \mathrm{~F}=7.88, P$ value $<0.001$

\section{Discussion}

The behavior, performance, and productivity of people in the workplace are somehow affected by the rate of burnout and mental workload. From an ergonomic and psychological point of view of the workplace, the rate of mental workload in certain situations can increase dramatically (7).

In this study, the scale of physical needs and the level of effort were the highest value in the total score of mental workloads. The rate of mental workload was higher in women, married employ-yees, and employees with a higher body mass index. Du and $\mathrm{Hu}$ assessed the mental workload of health care workers during the COVID-19 epidemic in a crosssectional study. They observed a high score under the subscales of effort, physical and mental demands among employees (21).

In general, the mean burnout of staff was higher than the mean reported in pre-pandemic conditions. The job burnout was higher in single people, people with age group and work experience and body mass index lower. In a study of the effects of the COVID-19 epidemic on mental workload and burnout, Lopez et al. examined 360 retail workers in Spain. The results of their study showed that the subjects suffered from 
a high volume of mental workload. They also rated the burnout levels of retail workers in the medium to high range (23).

In general, the rate of burnout and the mental workload was higher in populated medical centers such as the cities of Tehran and Isfahan.

\section{Conclusion}

The Covid-19 epidemic has been able to affect various physical and psychological dimensions of the work of medical staff, especially women, staff with direct contact with patients, and married staff.
Therefore, psychological interventions and supportive measures are necessary to maintain the health of employees.

\section{Acknowledgement}

The authors of the article thank the esteemed Vice Chancellor for Research and Technology of Kurdistan University of Medical Sciences for their financial support.

\section{Conflict of Interest}

The authors declared no conflict of interest. 


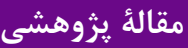

\section{ارزيابى بار كار ذهنى و فرسودگى شغلى كاركنان درمانى در دوران پاندمى كوويد-19 در ايران}

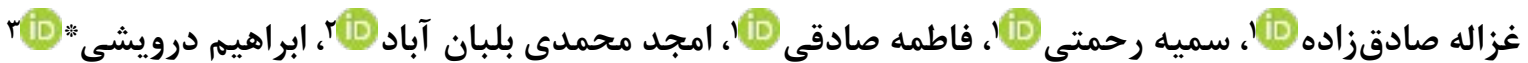

$$
\text { ' . . دانشجوى كارشناسى ارشد، گروه روانشناسى بالينى، دانشكده علوم انسانى، دانشكاه كردستان، سنندج، ايران }
$$

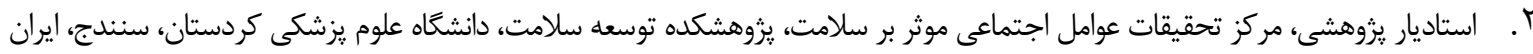

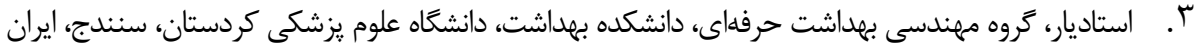

خلاصه

زمينه و هدف: هاندمى و بحران ناشى از كرونا با به خالش كشيدن تشكيلات و تمهيدات بهداشتى و

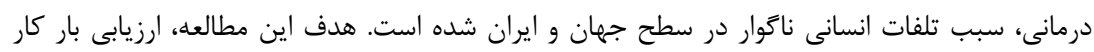

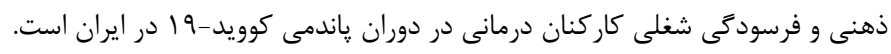

روش كار: يزوهش توصيفى- تحليلى حاضر روى • اله نفر از كاركنان درمانى و تشخيصى كه بلهورت تصادفى

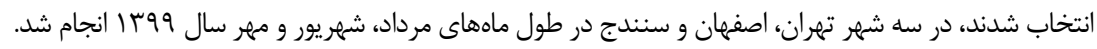

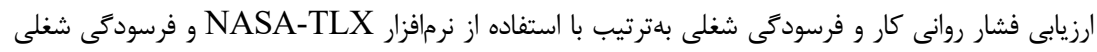

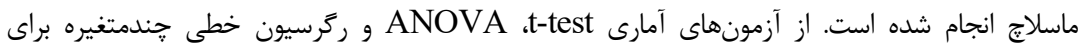

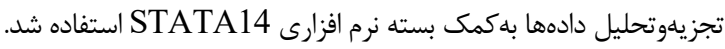

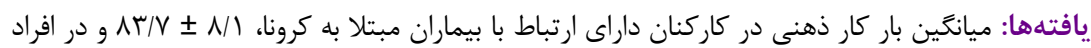
بدون ارتباط، 9/9

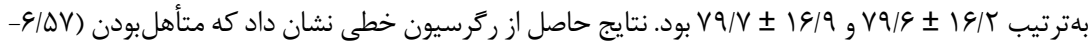
Sا coefficient= و كار در بيمارستانهاى اصفهان (IT/T/T)

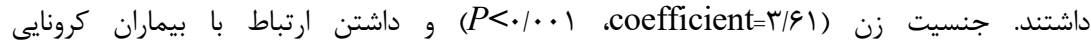
coefficient=ه/9) نتيجه كيرى: همهَيرى كوويد-19 بر ابعاد مختلف فيزيكى و روانى كارى كاركنان درمانى، بلويزه زنان و

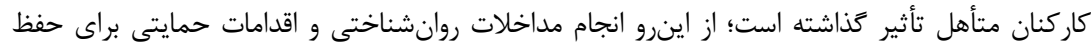
سلامتى كاركنان در دوران همهَيرى و بعد از آن ضرورى است. كليدوازهها: كوويد-9 1، فشار روانى كارى، فرسودگى شغلى، كاركنان درمانى

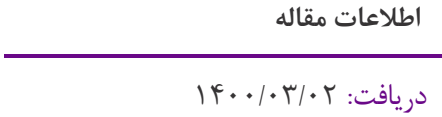

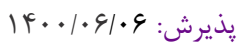 \\ | انتشار آنلاين: • • \\ نويسنده مسئول: \\ ابراهيم درويشى

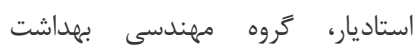 حرفهاى، دانشكده بهداشت، دانشعاه علوم \\ يزّكى كردستان، سنندج، ايران

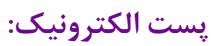

Darvishi,hse@gmail.com

براى دانلود اين مقاله، كد زير را

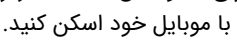

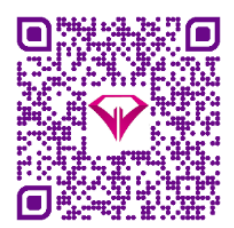

كجىرايت (C) مجله اركونومى؛ دسترسى آزاد؛

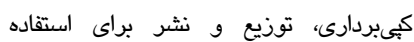

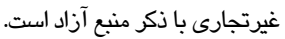

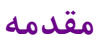

همراه داشته است. اخرجه آمار مشخص و دقيقى از مراجع

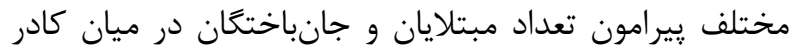

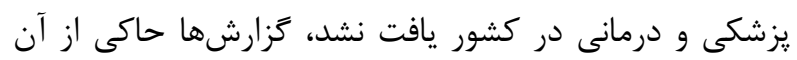

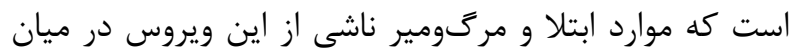
كاركنان و كادر درمانى، تشخيصى و خدماتى بيمارستانها نيز

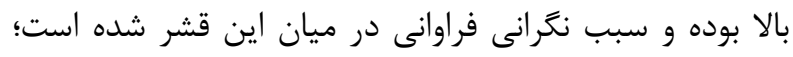

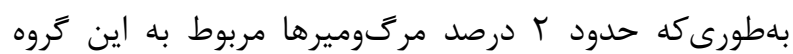

ظهور קֶاندمى و بحران ناشى از كرونا علاوه بر تلفات عمده

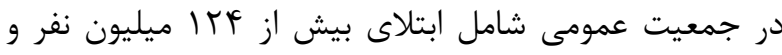

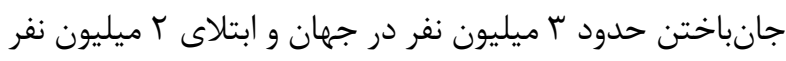

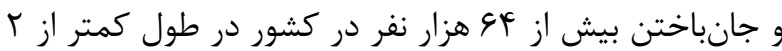

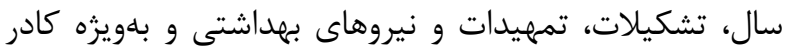

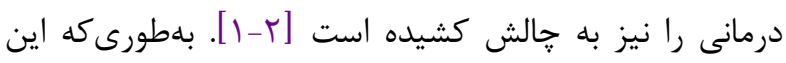

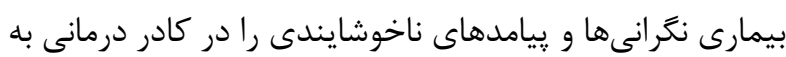


سندروم فرسودىى شغلى علاوه بر آسيبهاى شخصى، با كاهش

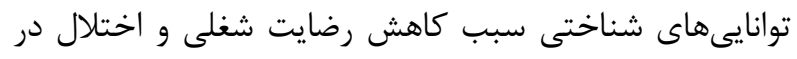

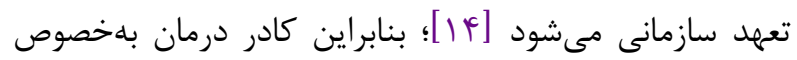

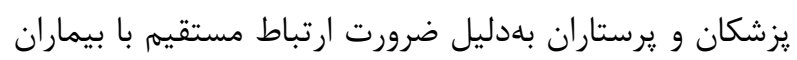

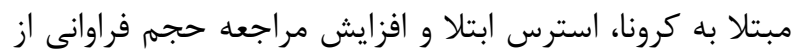

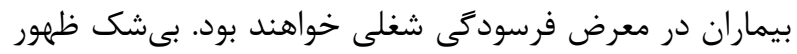

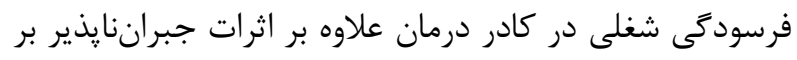

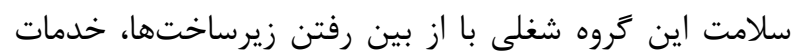

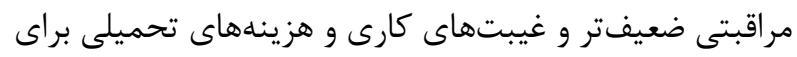

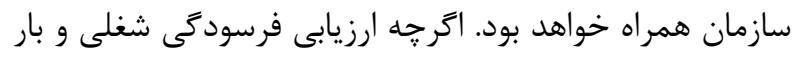
ذهنى كار كنان درمانى موضوعى جديد نيست، با توجه به شرايط إنى

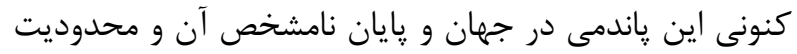

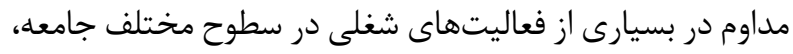

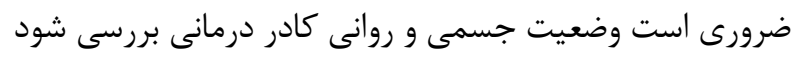
تا امكان اقدامات كنترلى و شغلى لازم از سوى سياست كذار إنى

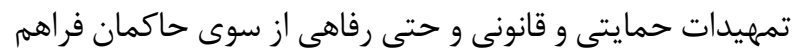

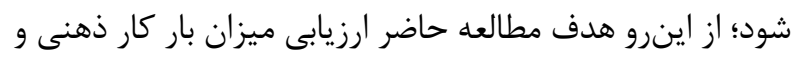

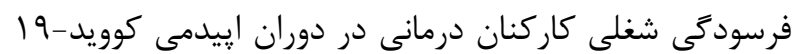
در سه شهر تهران، اصفهان و سنندج بود.

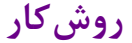

يروهش حاضر مطالعهاى توصيفى - مقطعى است كه در طول

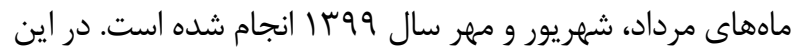
يزوهش، بهصورت تصادفى سه شهر اصفهان، تهران و سنندج

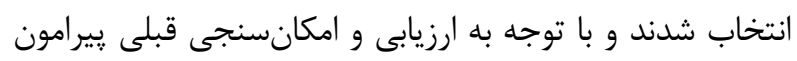

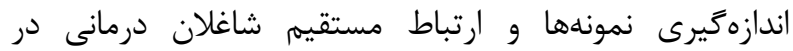

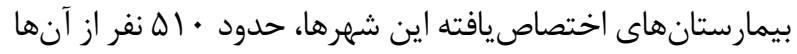

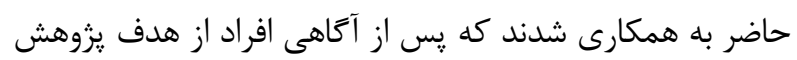

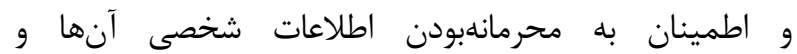

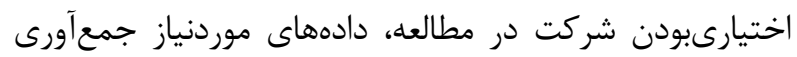

شد.

در اين مطالعه، ابزار يزوهش شامل سه يرسشنامه بود كه

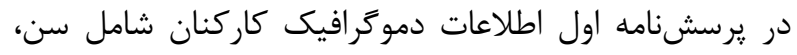

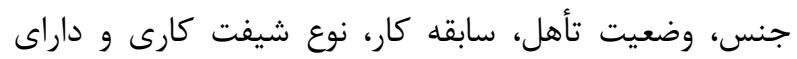

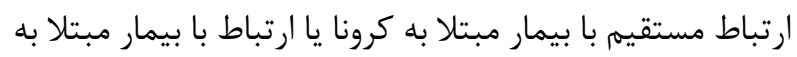
كرونا بود. يرسشنامه دوم، يرسشنامه ارزيابى بار كار ذهنى ناسا

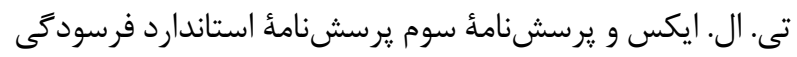

شغلى بوده است [ץ]. سازمان نظام يزشكى كشور اعلام كرده

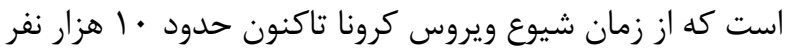

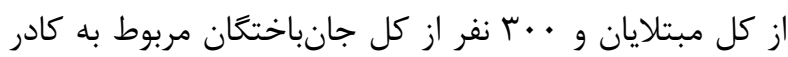

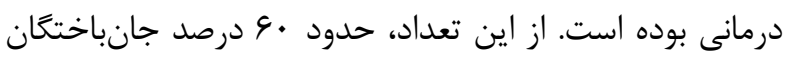

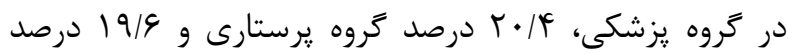

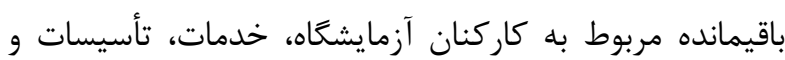

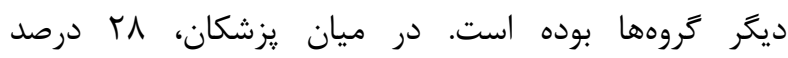

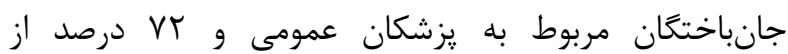
تخصصهاى مختلف بودهاند [ب]؛ بنابراين طبيعى است كادر

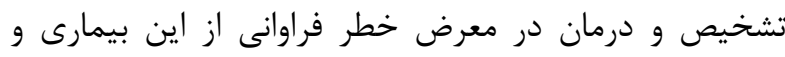

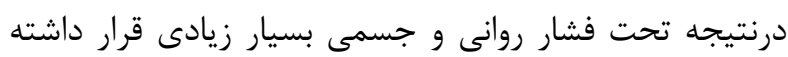
باشند.

تحمل فشار و تنش فيزيكى بالا بهدليل حجم فراوان

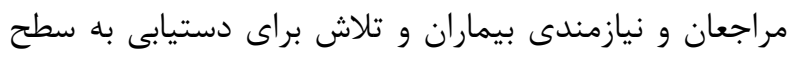

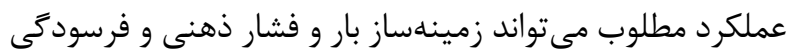

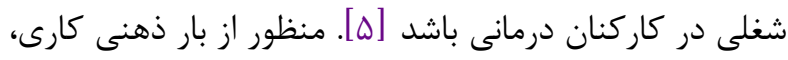

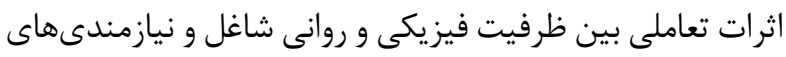

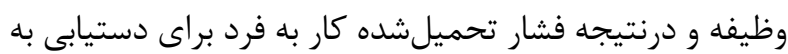

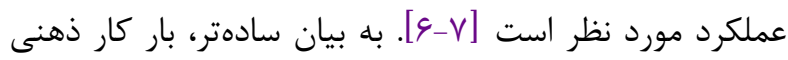

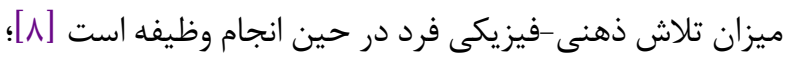

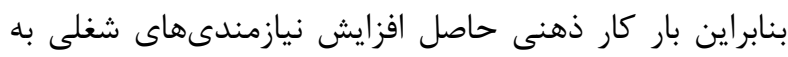

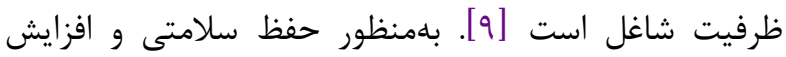
بهرهورى و كارايى شاغل در محيط كار، هدف منطقى اين است

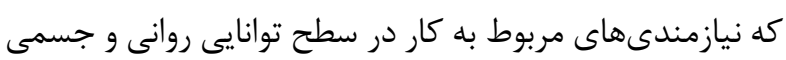

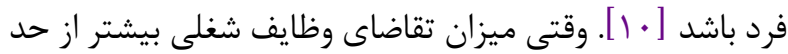
توان و ظرفيت شاغل باشد، زمينهساز افزايش فشار روانى و ونداني

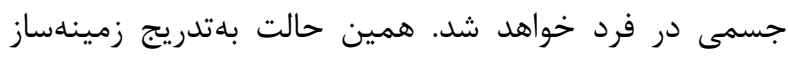
فرسودىى شغلى در كاركنان و درنتيجه سازمان نيز خواهد بود بود

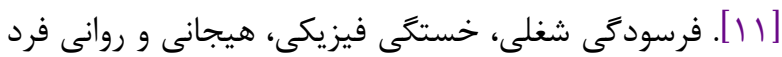

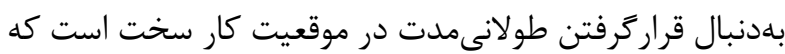

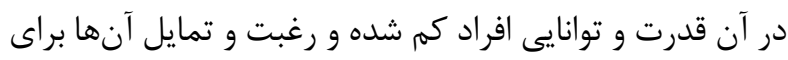

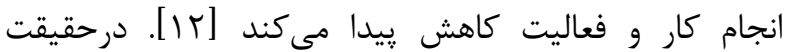

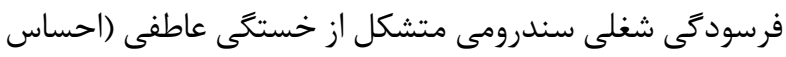

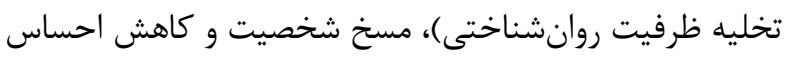
كفايت شخصى (كاهش احساس شايستگى و موفقيت در حرفه)

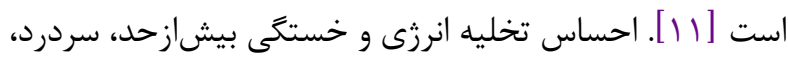

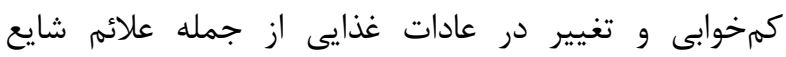

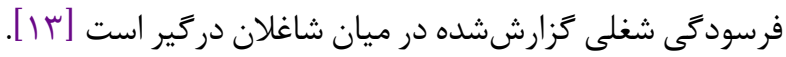


كسل كنندگى كه او در طول انجام كار احساس مى كند، سطحى از عملكرد و كارايى كه فرد تصور مى كند به آن دست يافته است و سطح سعى و تلاشى كه صرف انجام كار كرده است، از وى يرسيده مىشود. جز محور عملكرد و كارايى كه بين دو سطح خوب و بد ارزيابى مى شود، ساير محورها بين دو سطح كمم و زياد

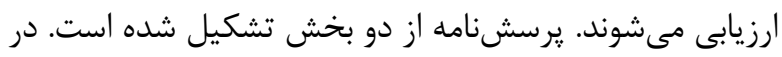

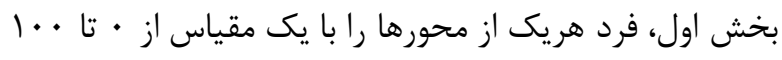

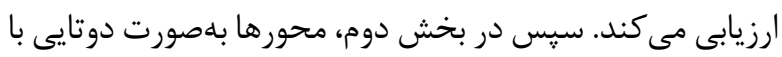
هم مقايسه مىشوند و فرد محورى را مشخص مى كند كه تأثير

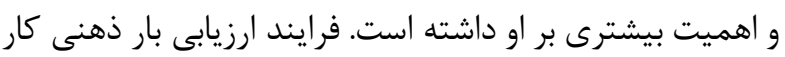
هم با استفاده از آن، شامل سه مرحله است. مرحله اول، تعيين وزن بار (Weighting)، مرحله دوم، تعيين درجه بار (Rating) و

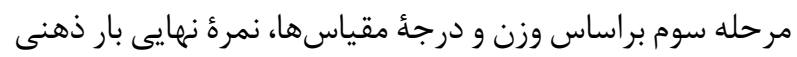

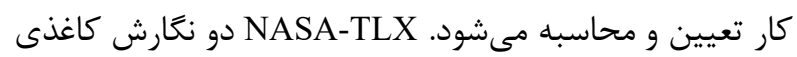

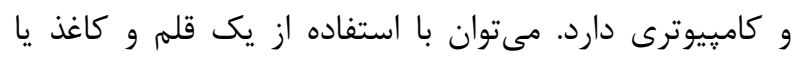

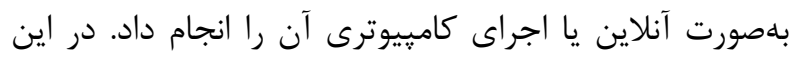

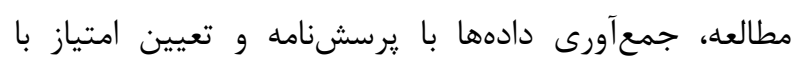
استفاده از روش نرمافزارى NASA-TLX انجام شد. اعتبار و و

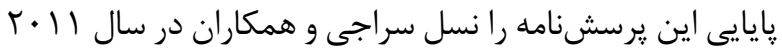
در مطالعهاى كه در رابطه با بار كارى يرستاران انجام شد مورد برد

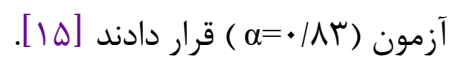

شغلى ماسلاخ' بود كه از رايجترين ابزار اندازهيرى فرسودىى

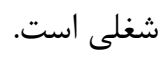

\section{ارزيابى بار كار ذهنى}

در مرحلة اول، دادههاى مربوط به متغيرهاى زمينهاى در لرد جامعهُ مورد مطالعه به همراه ميزان بار كار ذهنى با استفاده از مرحئ يرسشنامه تخصصى بار كار ذهنى ناسا' جمعآورى شد [ع] يرسشنامهُ ناسا تى. ال. ايكس را اولين بار ساندرا هارت در سال

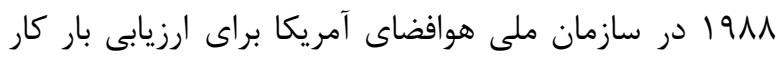

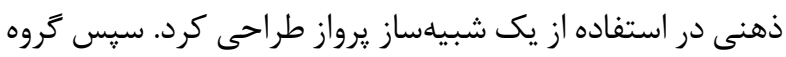
كارايى انسانى (Human Performance Group) در مركز

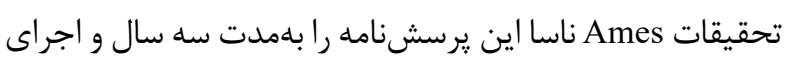

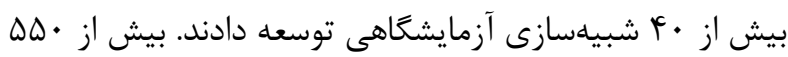
يزوهش بهكمى آن انجام شده است، اما بهتدريج در بسيارى از از مشاغل ديخر به كار گرفته شد. شاخص تحمل بار كارى ناسا

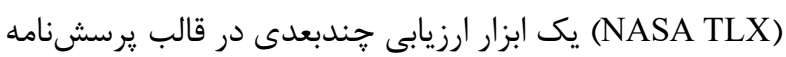
بوده و هدف آن ارزيابى و سنجش حجم و فشار ادراكى يك كار يا فعاليت خاص، يك سيستم، كارايى و اثربخشى يك گروه يا

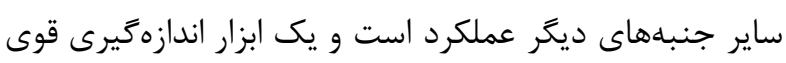
بار كارى ذهنى است كه در شش محور، بار كارى را به روش ذهنى ارزيابى مى كند. اين يرسشنامه بار فكرى، بار فيزيكى و

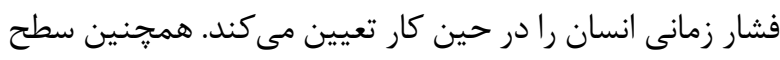

جدول ا. مقياسهاى بار كار ذهنى در روش NASA- TLX

\begin{tabular}{|c|c|c|}
\hline 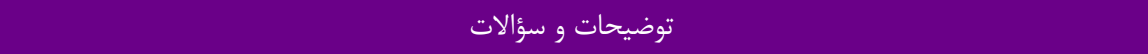 & 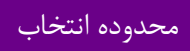 & مقياسها \\
\hline 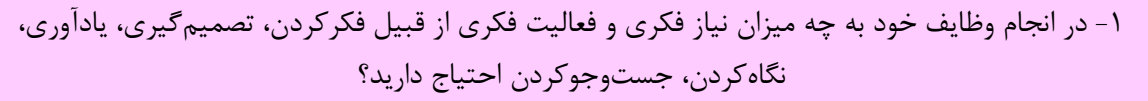 & خيلى زياد/خيلى & نيازمندى ذهاى \\
\hline 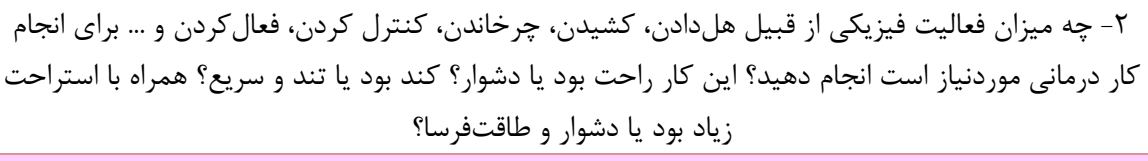 & خيلى زياد/خيلى & فيزازمنديهاى فيكى \\
\hline ז- جه ميزان فشار زمانى به دليل سرعت بالاى انجام هر فعاليت احساس مى كنيد؟ & خيلى زياد/خيلى & 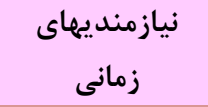 \\
\hline ץ- أ از نظر ذهنى يا فيزيكى جه اندازه ناجار به تلاش هستيد تا به سطح كارايى دلخواه برسيد؟ & خيلى زياد/خيلى & 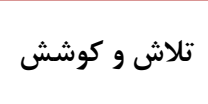 \\
\hline ه- تا جه ميزان بايد كار كنيد تا به سطح عملكرد دلخواه برسيد؟ جقدر از ميزان كاركرد خود رضايت داريد؟ & 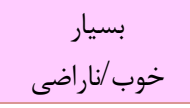 & 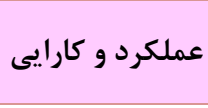 \\
\hline צ- جقدر احساس نامنى، دلسردى، خشم، استرس و رنجش به دليل شرايط كارى داريد؟ & خيلى زياد/خيلى & سرخوردَى \\
\hline
\end{tabular}


دادههاى بهدستآمده از نرمافزار NASA و يرسشنامة فرسودگى

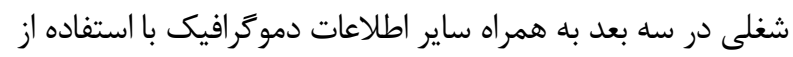

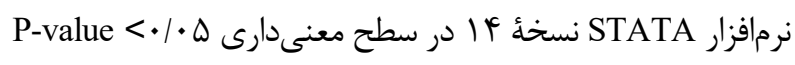

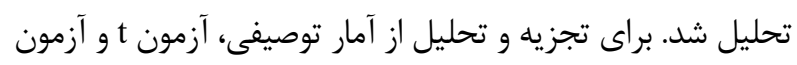
ANOVA

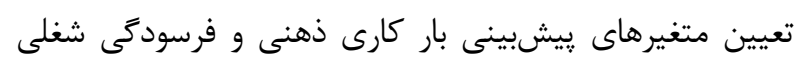

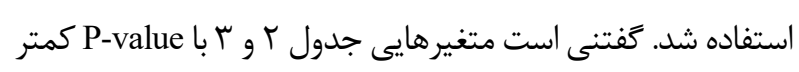
از آ • بلعنوان متغير مستقل وارد مدل شدند.

يافته ها

در اين مطالعه •lله نفر از كاركنان درمانى در سه شهر

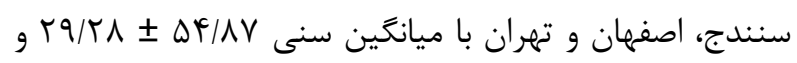

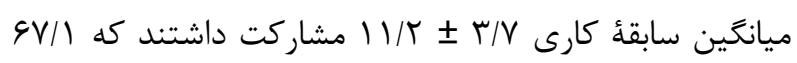

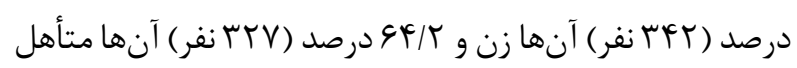
بودند. بيشتر مشاركت كنند

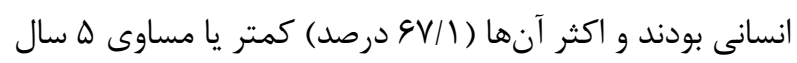

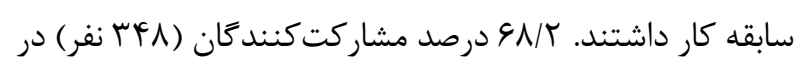

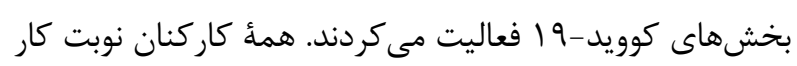

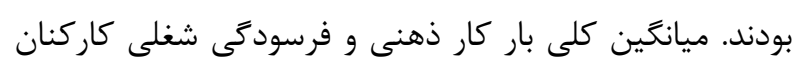

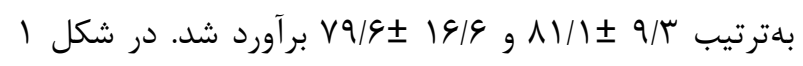
مقادير كلى بار كار ذهنى و فرسودگى شغلى كاركنان به همراه مقياسهاى مربوط آمده است.

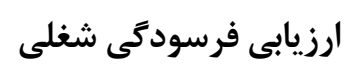

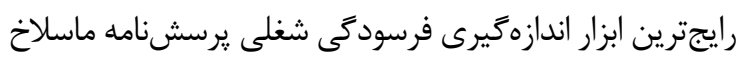

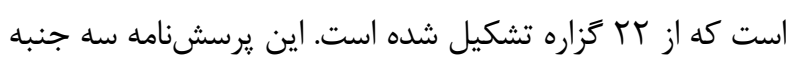

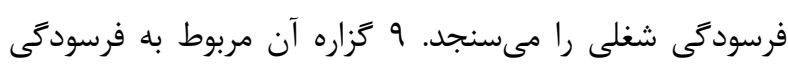

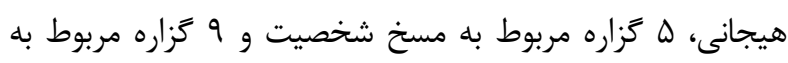

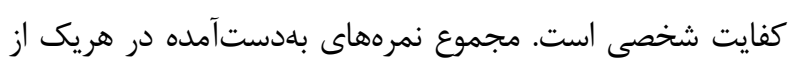

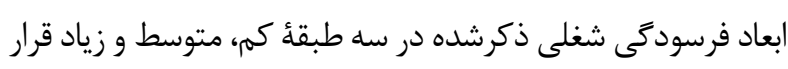

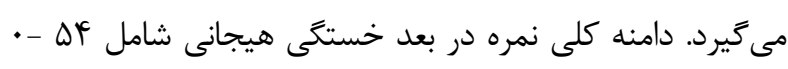

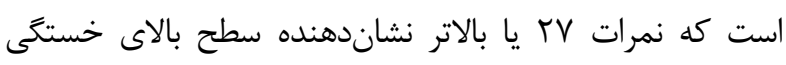

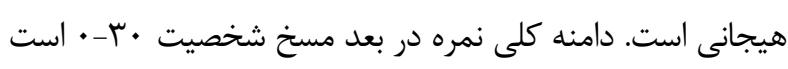

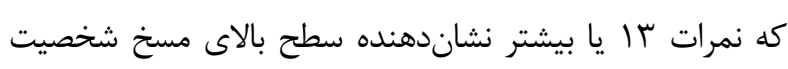

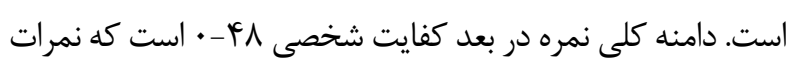

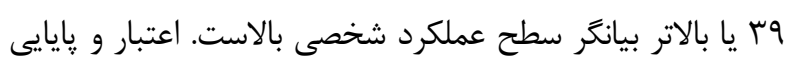

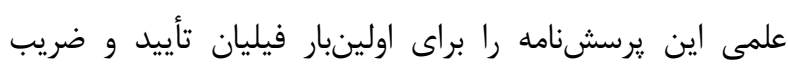

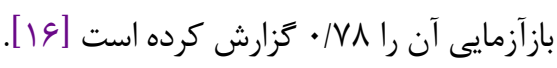

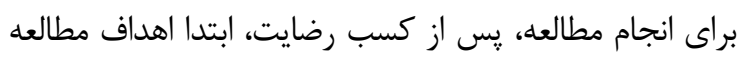

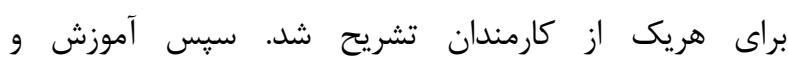

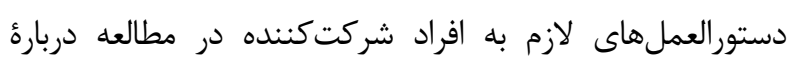

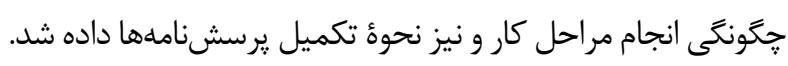

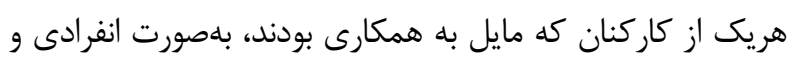
در خلال كارى خود برسش نامهها را تكميل كردند.

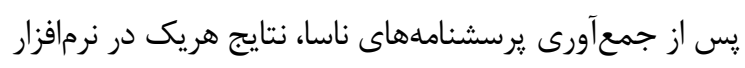

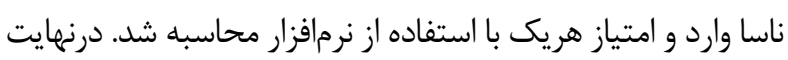

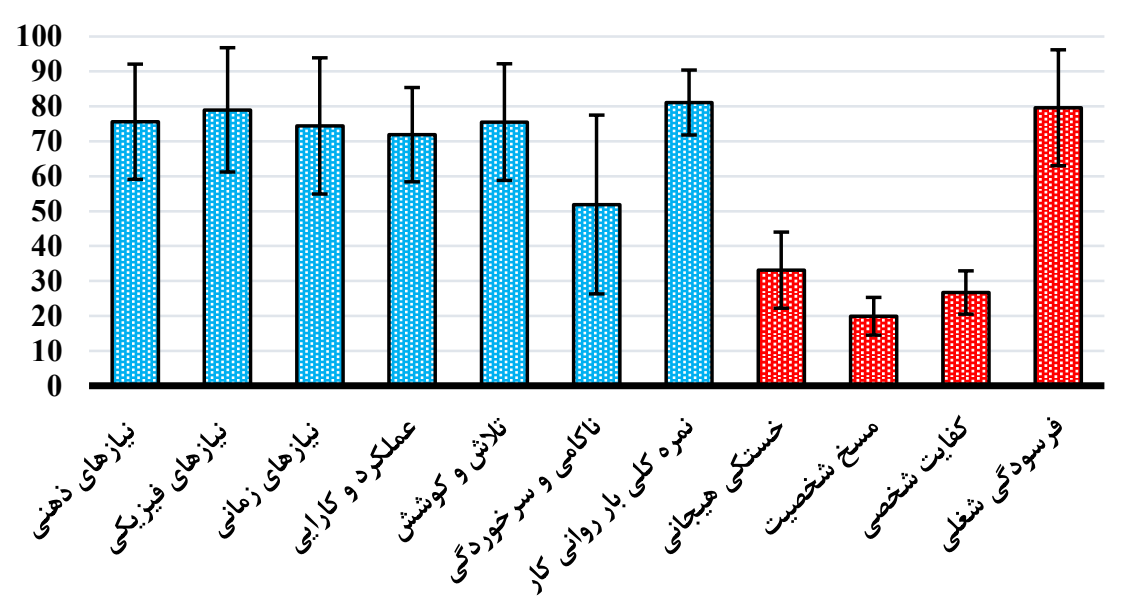

شكل ا- ميانغين بار كار ذهنى و فرسودىى شغلى كاركنان به همراه زيرمقياسهاى هر يك از آنها

درمانى زن و متأهل هستند. همٍنين براساس نتايج، بيشتر

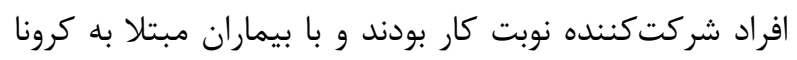
ارتباط مستقيم داشتهاند.
ميانخين و انحراف معيار بار كار ذهنى و فرسودگى شغلى

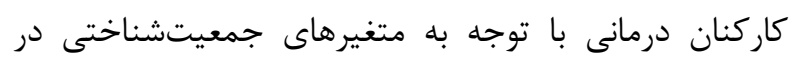
جدول r آمده است. همانطور كه مشخص است، بيشتر كاركنان 


\begin{tabular}{|c|c|c|c|c|c|c|c|c|}
\hline \multirow[b]{2}{*}{ P-value } & \multicolumn{2}{|c|}{ فرسودَى شغلى } & \multirow[b]{2}{*}{ P-value } & \multicolumn{2}{|c|}{ فشار روانى كارى } & \multirow[b]{2}{*}{ درصد } & \multirow[b]{2}{*}{ تعداد } & \multirow[b]{2}{*}{ متغير } \\
\hline & انحراف & ميانغين & & انحراف & ميانگين & & & \\
\hline & & & & & & & & جنسيت \\
\hline \multirow{2}{*}{${ }_{* *} \cdot / 4 R I$} & $\mid N / T$ & $\Lambda \cdot / \Lambda$ & \multirow{2}{*}{${ }^{* *} \cdot / \cdot r$} & $1 \cdot 10$ & $V q / f$ & $r r / q$ & 194 & مرد \\
\hline & $1 \Delta / V$ & $\vee 9 / 1$ & & $N / \Delta$ & $11 / 9$ & $9 V / 1$ & MAT & 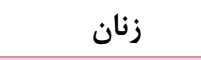 \\
\hline & & & & & & & & وضعيت تأهل \\
\hline \multirow{2}{*}{${ }^{* *} \cdot / \cdot \cdot 1$} & $\mid f / T$ & $\Lambda r / V$ & \multirow{2}{*}{${ }^{* *} \cdot / \cdot 19$} & $1 / 9$ & $\vee 9 / v$ & $r \Delta / \Lambda$ & INT & مجرد \\
\hline & $I V / F$ & $V V / A^{q}$ & & $9 / 9$ & $11 / 1$ & $s F / T$ & rtV & متأهل \\
\hline & & & & & & & & كروه سنى \\
\hline \multirow{4}{*}{$* * * . / . r$} & $\mid F / \Lambda$ & VN/G & \multirow{3}{*}{$* * * \cdot / . .4$} & $1 \cdot / 4$ & $V \wedge / 9$ & $T V / G$ & 119 & $\leq r \Delta$ \\
\hline & $|V /|$ & $11 / 4$ & & $\Lambda / 9$ & NT & $\Delta N / q$ & rqV & $r \Delta-r \Delta$ \\
\hline & $19 / \pi$ & $V r / 9$ & & $N / r$ & $1 \cdot 19$ & $1 r / \Delta$ & $9 \Lambda$ & $\geq r \Delta$ \\
\hline & & & & & & & & سابقه كارى \\
\hline \multirow{4}{*}{${ }^{* * *} \cdot / \cdot 1$} & $19 / 1$ & $\Lambda \cdot / 4$ & \multirow{3}{*}{${ }^{* * *} \cdot / 1 \cdot \wedge$} & $9 / 1$ & $1 \cdot 10$ & $\varepsilon V / I$ & MIF & $\leq \Delta$ \\
\hline & $I V / \Delta$ & $\Lambda \Delta / \vee$ & & $1 \cdot 11$ & $\Lambda r / \Lambda$ & $1 N / T$ & $\wedge \Delta$ & $\Delta-1$ \\
\hline & $19 / V$ & $V T / F$ & & $\mathrm{~V} / \Lambda$ & $\Lambda \cdot 19$ & $\mid F / V$ & 99 & $\geq 1$. \\
\hline & & & & & & & & نر ايط استخدام \\
\hline \multirow{4}{*}{${ }^{* * *} \cdot / \cdots 1$} & $\mid r / T$ & NT & \multirow{3}{*}{${ }^{* * *} \cdot 1 \cdot 19$} & $1 / 9$ & $\wedge \varepsilon / \wedge$ & r & $r \cdot$ & رسمى \\
\hline & $I V / V$ & $\Lambda r / r$ & & $9 / 0$ & $\Lambda \cdot / V$ & $F \Delta / V$ & Lו & ي يمانى \\
\hline & $\mid Q / 1$ & $V \& / V$ & & $9 / 1$ & $11 / \pi$ & $\Delta \cdot / T^{c}$ & $r \Delta \Delta$ & طرحى \\
\hline & & & & & & & & لاخص توده بدن \\
\hline \multirow{4}{*}{${ }^{* * *} \cdot / \cdot 1$} & $\mid F / \Delta$ & $1 \mathrm{~N} / 9$ & \multirow{3}{*}{${ }^{* * *} \cdot / \cdot r$} & $9 / 9$ & $\Lambda \cdot / 4$ & rr/f & IFD & $\leq r \Delta$ \\
\hline & $19 / 1$ & $v \varepsilon / r$ & & $1 \cdot / V$ & $\Lambda \cdot 19$ & $\Delta r / r$ & Tl & $r \Delta-r \cdot$ \\
\hline & $\mid r / \Lambda$ & $v \cdot / 1$ & & $9 / 1$ & $\Lambda \Delta / 1$ & $\mid r / F$ & $\Delta \Lambda$ & $\geq r$. \\
\hline & & & & & & & & شهر \\
\hline \multirow{3}{*}{$* * * \cdot 1 \cdots 1$} & $I T / V$ & $v \cdot / 9$ & \multirow{3}{*}{${ }^{* * *} \cdot 1 \cdot .1$} & $9 / 1$ & $\Lambda r / 1$ & $r \Delta / r$ & 11 & سندج \\
\hline & $18 / 4$ & $\Lambda V / r$ & & $9 / \Gamma$ & $9 \Delta / \Delta$ & $\varphi \varepsilon / \pi$ & וTr & اصفهان \\
\hline & $\mid f / \Delta$ & $V V / F$ & & $1 / 9$ & $\Lambda r / r$ & $\mid N / T^{f}$ & 94 & تهران \\
\hline- & $19 / 9$ & $\vee 9 / 9$ & - & $9 / \Gamma$ & $11 / 1$ & & & كل \\
\hline
\end{tabular}

** Based on T-test *** Based on ANOVA test

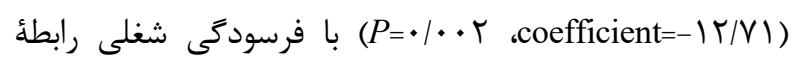
معكوسى داشتند، اما كار در ب بيمارستانهاى اصفهان

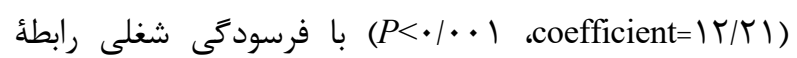

$$
\text { مستقيمى داشت (جدول \&). }
$$

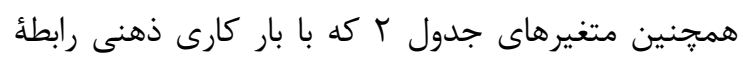

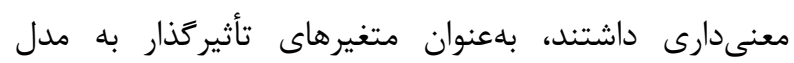

همجنين ابعاد فشار روانى و فرسودگى شغلى كاركنان داراى ارتباط و بدون ارتباط با بيماران مبتلا به كرونا در جدول r تحليل شده است.

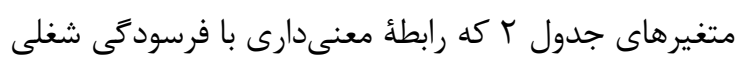
داشتند، بهعنوان متغير تأثير گذار در مدل ركرسيون وارد شدند.

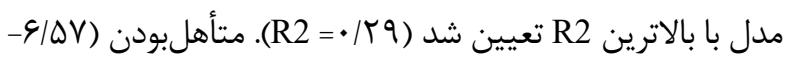
coefficient= 
كار ذهنى رابطؤ مستقيمى داشتند، اما كار در بيمارستانهاى

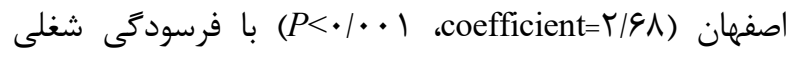
رابطة معكوسى داشت (جدول ه).

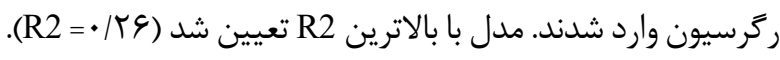

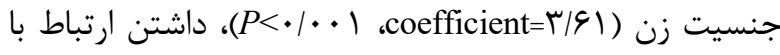
بيماران كرونايى (Poefficient=Q/9،

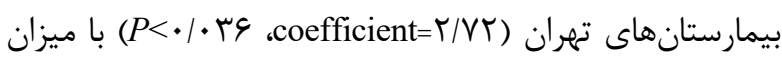

جدول rا. ميانكَين و انحراف معيار و سطح معنادارى ابعاد بار كار ذهنى و فرسودىى شغلى كليه كاركنان با و بدون ارتباط با بيماران مبتلا به كرونا

\begin{tabular}{|c|c|c|c|c|c|}
\hline \multirow{3}{*}{ P-value } & \multicolumn{2}{|c|}{ بدون ارتباط با بيمار كرونايى } & \multicolumn{2}{|c|}{ ار تباط با بيمار كرونايى } & \multirow{3}{*}{ 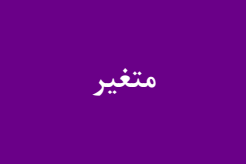 } \\
\hline & \multicolumn{2}{|c|}{$N=I F Y$} & \multicolumn{2}{|c|}{$\mathbf{N}=\mathbf{r} \boldsymbol{F}$} & \\
\hline & انحراف معيار & ميانغين & انحراف معيار & ميانغين & \\
\hline & & & & & فشار روانى كارى \\
\hline$\cdot 1 \cdot 94$ & $|\varepsilon| \cdot$ & $V F / T$ & $I V / T$ & $\vee \wedge / \Delta$ & فشار ذهنى \\
\hline$\cdot 1 \cdot 11$ & $19 / \mathrm{V}$ & $V V / G$ & $19 / 1$ & $11 / 9$ & فشار فيزيكى \\
\hline .1190 & $1 / N$ & $V T / d$ & TI/V & Vब/I & فشار زمانى \\
\hline$\cdot 10 \cdot V$ & $|F /|$ & $V T / T$ & $\mid r / T$ & $V \backslash / 4$ & عملكرد و كارايى \\
\hline$\cdot 1 \cdot \cdot 1$ & $19 / 4$ & $V \mu / f$ & $19 / 0$ & $1 \cdot / 1$ & تلاش و كوشش \\
\hline . /rqp & $r F / l$ & $\Delta T / Q$ & TN/G & $\Delta \cdot / \Delta$ & ناكامى و سرخوردگىى \\
\hline$\cdot 1 \cdot \cdot 1$ & $9 / 9$ & $\vee q / 9$ & $1 / 1$ & $\Lambda r / V$ & نمره كل \\
\hline & & & & & فرسودى شغلى \\
\hline.$/ 19$. & $1 \cdot 1 \cdot$ & rT/Q & $1 \cdot 11$ & $r r / q$ & خستخَى هيجانى \\
\hline$\cdot 1 \cdot \cdot 1$ & $\Delta / V$ & $r \cdot / 9$ & $\varphi / 1$ & $1 N / \Delta$ & مسخ شخصيت \\
\hline$\cdot / \pi \cdot 9$ & $9 / 9$ & $r \& / D$ & $\Delta / 1$ & $r V / l$ & كفايت شخصى \\
\hline ./941 & 1911 & $\mathrm{Vq} / \mathrm{V}$ & $19 / \pi$ & $V 9 / 9$ & نمره كل \\
\hline
\end{tabular}

\begin{tabular}{|c|c|c|c|c|c|}
\hline فاصله اطمينان ه9٪٪ & P-value & $T$ & Std.B & $B$ (coefficient) & متغير \\
\hline $0 \cdot / 1 r .99 / 19$ & $<\cdot 1 \cdots 1$ & 9199 & 19199 & $V / / l^{f}$ & Constant \\
\hline$-\cdot / \cdot F, I / Q V$ & .1 .94 & $1 / \wedge 9$ & $\cdot|q|$ & $\cdot / V V$ & سن \\
\hline \multirow[t]{2}{*}{$-1 / 9 V \cdot \cdot / \cdot r$} & $\cdot / \cdot \Delta V$ & $-1 / 91$ & Tr & $-\cdot / \Lambda r$ & سابقه كار \\
\hline & & & & & شاخص توده بدن \\
\hline$-9 / 0 r .1 / 19$ & $\cdot / I \vee \Delta$ & $-1 / \% 9$ & 1/94 & $-Y / 9 V$ & $r \cdot-r \Delta$ \\
\hline \multirow[t]{2}{*}{$-1 \cdot / 91 \cdot \cdot / 94$} & .1 .99 & $-1 / 99$ & $r / r$ & $-Q / \cdot r$ & $\geq r$. \\
\hline & & & & & وضعيت تأهل \\
\hline \multirow[t]{2}{*}{$-1 \cdot / \wedge \Delta,-r / r q$} & $\cdot 1 \cdot r$ & $-r / \cdot r$ & T/IV & $-9 / 0 V$ & متأهل \\
\hline & & & & & شرايط استخدام \\
\hline$-I T / 9 F ، I / T V$ & $\cdot 11 \cdot r$ & $-1 / 94$ & r/AV & - & پِيمانى \\
\hline \multirow[t]{2}{*}{$-r \cdot \mid \Delta \Phi,-r / A V$} &.$/ \cdot r$ & $-r / 19$ & r/99 & $-|Y / V|$ & طرحى \\
\hline & & & & & شهر \\
\hline V/AY ،IG/DV & $<\cdot \mid \cdot \cdot 1$ & $\Delta / 4 q$ & T/TY & $|r / T|$ & اصفهان \\
\hline$-1 / \cdot r \cdot V / V q$ & . / & $1 / \Delta 1$ & T/YF & r/r & ت ت تهران \\
\hline
\end{tabular}


جدول ه-نتايج آناليز مدل ركرسيون خطى براى بيشبينى بار كار ذهنى

\begin{tabular}{|c|c|c|c|c|c|}
\hline فاصله اطمينان \$9 \$1 & P-value & $T$ & Std.B & $B$ (coefficient) & متغير \\
\hline$V \cdot / \cdot V$. AF/VT & $<\cdot / \cdot \bullet 1$ & $r \cdot / V G$ & $r / v r$ & $V \varepsilon / T^{q}$ & Constant \\
\hline \multirow{2}{*}{$-1 / 10 \cdot \cdot / 19$} & $\cdot 1 \cdot \cdot V$ & $\cdot / 4 \Lambda$ & $\cdot 1 \cdot \wedge$ & $\cdot 1 \cdot r$ & سن \\
\hline & & & & & جنسيت \\
\hline \multirow[t]{2}{*}{ I/AF، D/RG } & $<+1 \cdot+1$ & $F / \cdot r$ & $\cdot 119$ & $r|q|$ & 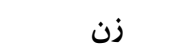 \\
\hline & & & & & اخص توده بدن \\
\hline$-F / F r . \cdot 1 \cdot q$ & $+|+F|$ & $-1 / \Lambda \Lambda$ & $1 / 10$ & $-r / 19$ & $r \cdot-r \Delta$ \\
\hline \multirow[t]{2}{*}{ 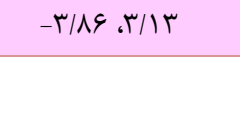 } & $\cdot \mid V M I$ & $-\cdot|r|$ & $1 / V V$ & $-\cdot / T 9$ & $\geq$ r. \\
\hline & & & & & وضعيت تأهل \\
\hline \multirow[t]{2}{*}{$-\bullet / 19 ، 6 / \Lambda 1$} & $\cdot / \cdot V$ & I/AT & $1 / T V$ & T/T & متأهل \\
\hline & & & & & 'نرايط استخدام \\
\hline$-F / F V, F / \varphi$. & $\cdot / 9 \mathrm{VV}$ & $\cdot / \cdot r$ & $T / \mu 1$ & $\cdot 1 \cdot 9$ & ي ييمانى \\
\hline \multirow[t]{2}{*}{$-\Delta / 9) ، \pi / \Delta V$} & $.19 T \Lambda$ & $-\cdot / 4 \Lambda$ & $r / 4)$ & $-1 / 1 V$ & طرحى \\
\hline & & & & \multicolumn{2}{|c|}{ ارتباط با بيماران كرونايى } \\
\hline \multirow[t]{2}{*}{ 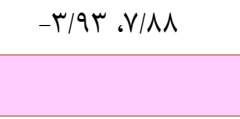 } & $<\cdot / \cdot \cdot 1$ & $\mathrm{Q} / \mathrm{\Lambda \Lambda}$ & 1 & $\Delta / 9$ & دارد \\
\hline & & & & & شهر \\
\hline$-\Delta / r T \cdot-\cdot / \cdot r$ & $\cdot 1 \cdot 49$ & $\Delta / \uparrow q$ & $-Y / \cdot$ & $-r / 9 \Lambda$ & اصفهان \\
\hline •/ / V ه/Vq & . & $1 / 01$ & $r / l \cdot$ & T/VT & تهران \\
\hline
\end{tabular}

$\mathrm{R} 2=0.26, \mathrm{~F}=7.88, \mathrm{P}$-value $<0.001$

Zakerian و همكاران [1/1] در مطالعة خود 99/V، Sarsangi و

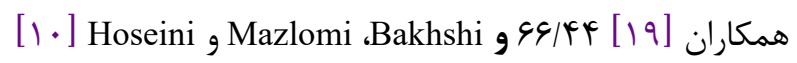

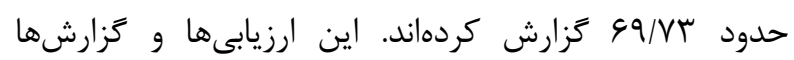
بلسادگى تأييدكننده ادعاى پايينبودن فشار روانى كاركنان درمانى در ييش از ظهور و إييدمى كروناست.

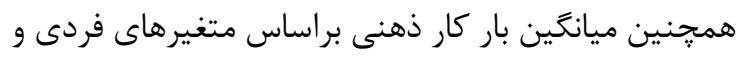

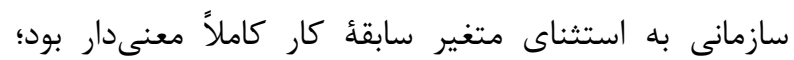

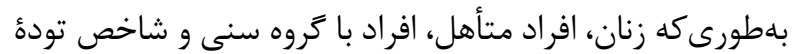
بدنى بالاتر و نيز افراد با شرايط استخدام رسمى از از ميانگين

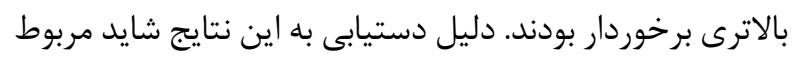

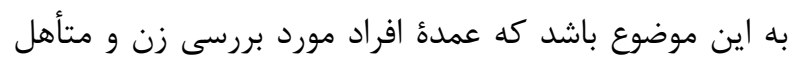

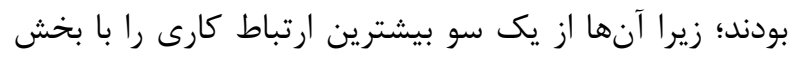

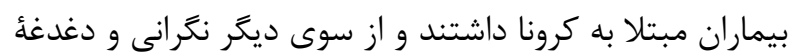

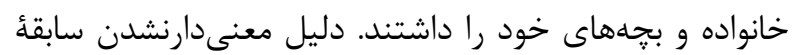

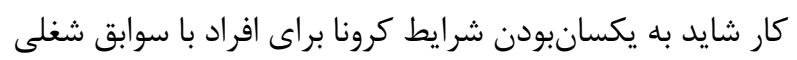

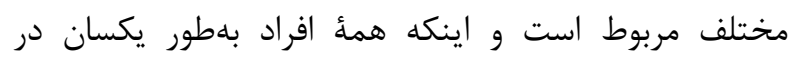

در هر شغلى درجه و محدودهٔ نرمالى از بار ناشى از كار به

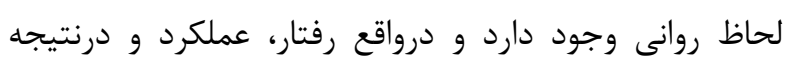
بهرهورى افراد در محيط كار بهنوعى تحت تأثير بار كار ذهنى

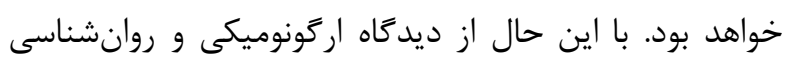
محيط كار ميزان فشار روانى در شرايط خاص مى تواند بهشدت

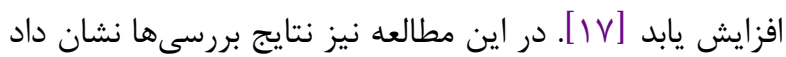

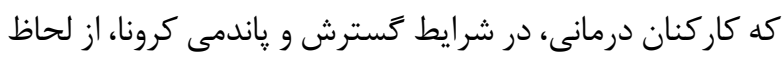
روانى داراى درجهُ خاصى از بار كارى هستند؛ بهطورى كه نتايج

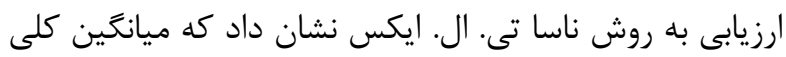

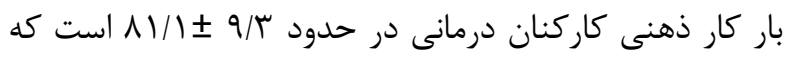

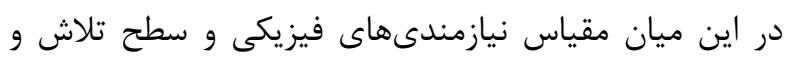
كوشش بيشترين ميزان را در نمره كلى داشتند. مقايسٔ نتايج

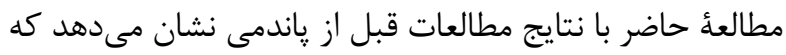

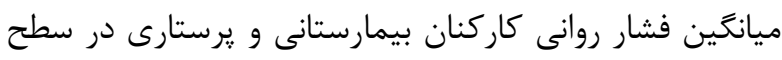

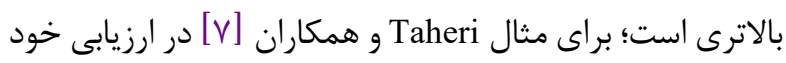

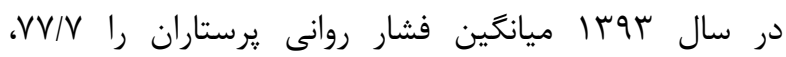


كزارش كردهاند. در همأ اين مطالعات درصد كاركنان زن و نوبت

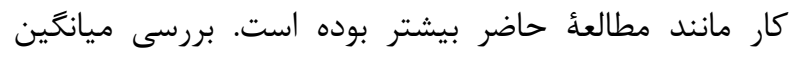

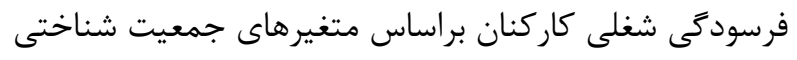

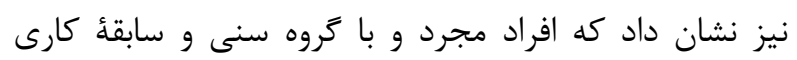

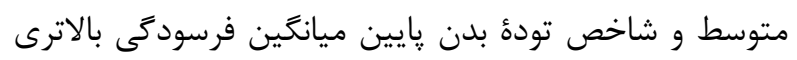

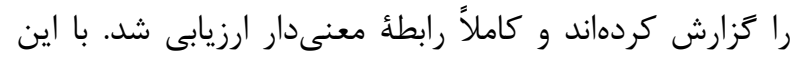

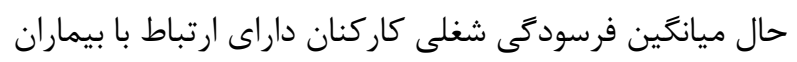

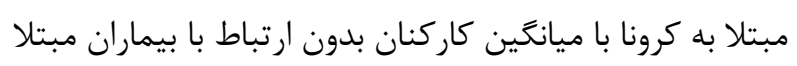

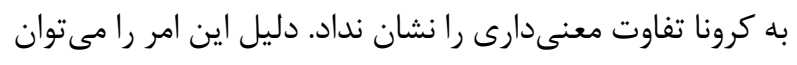

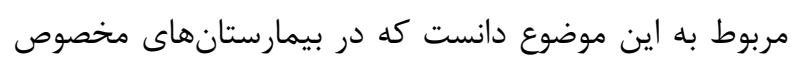

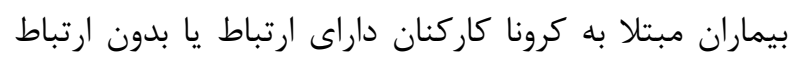
داراى وظايف شغلى و سطح فعاليت نزديك به يكديكر بودند.

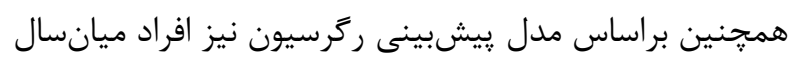

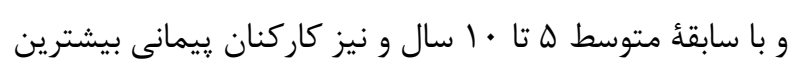

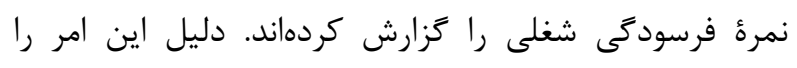

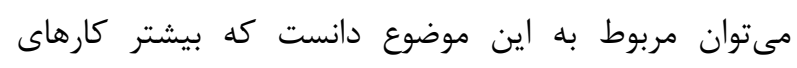

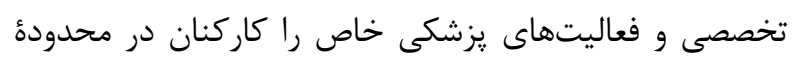

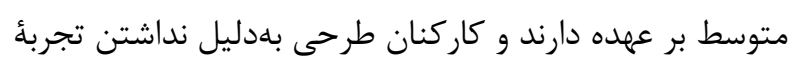

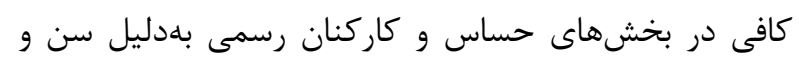

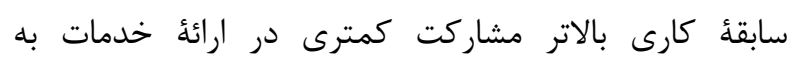

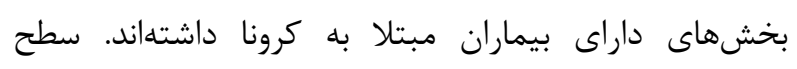

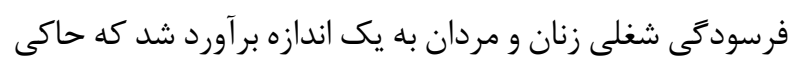

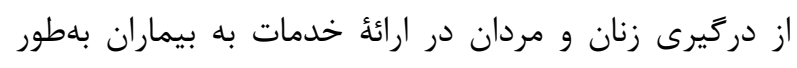

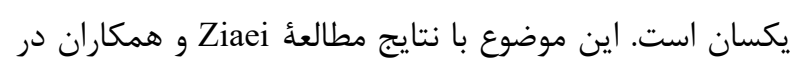
شرايط قبل از ظهور كرونا نيز همخوانى دارد [هان].

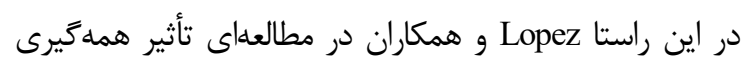
كوويد-19 بر بار كار ذهنى و فرسودىى شغلى . عب نفر از كاركران

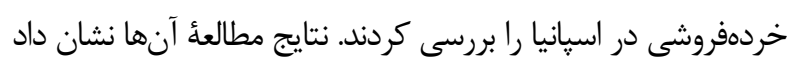

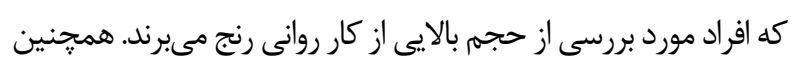

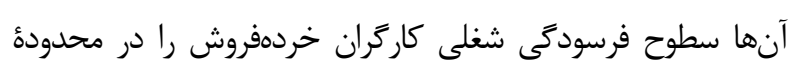
متوسط تا زياد ارزيابى كردند كه با علائمى از قبيل دردهاى فراى جسمانى،

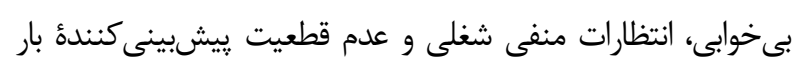

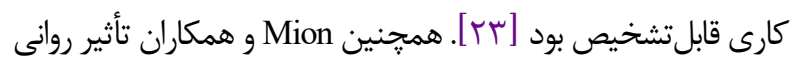

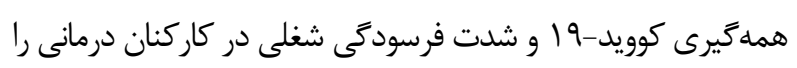

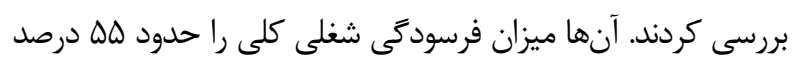

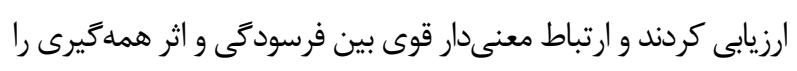

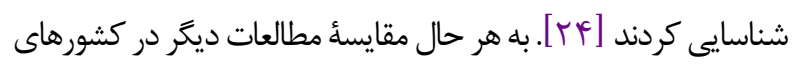

فعاليتهاى مورد نظر دركير بودهاند. نتايج تحليل آمارى نيز

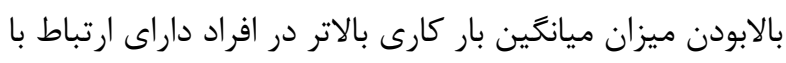

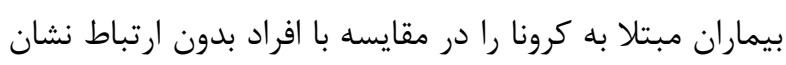

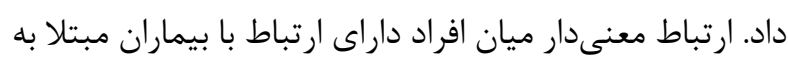

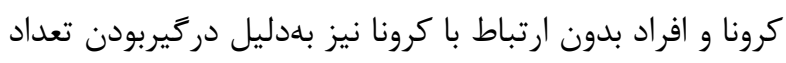

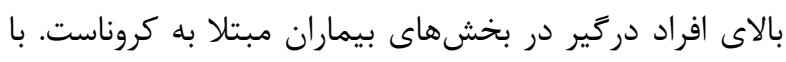

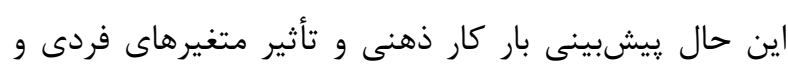

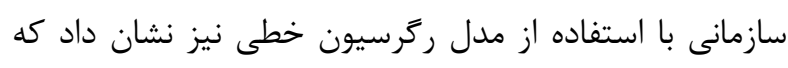

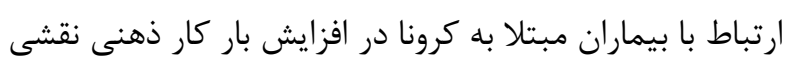

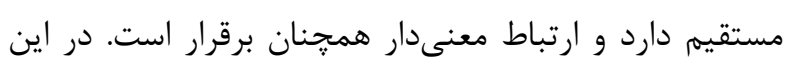

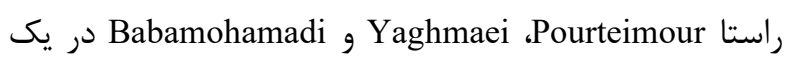

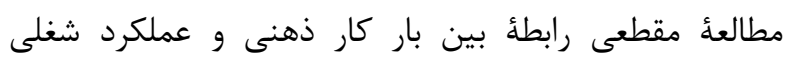

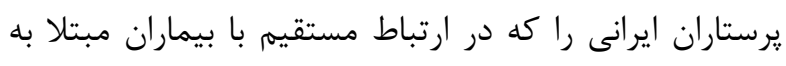

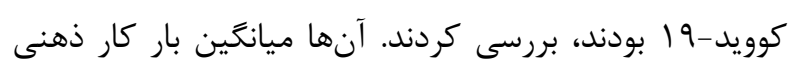

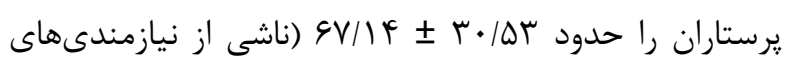

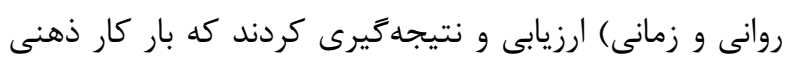

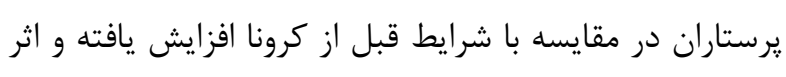

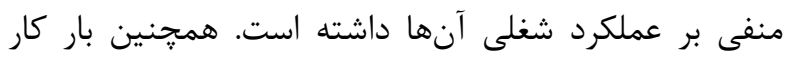

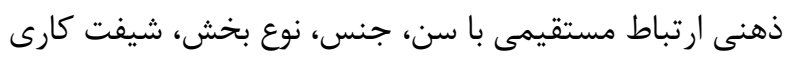

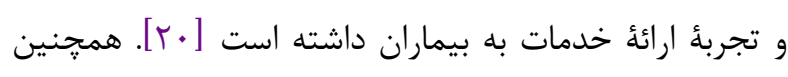
طu Du

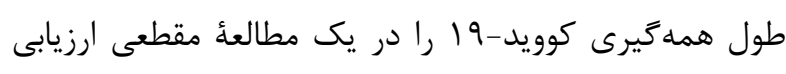

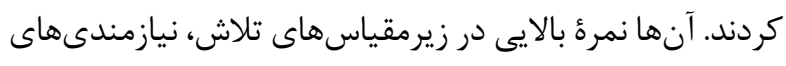

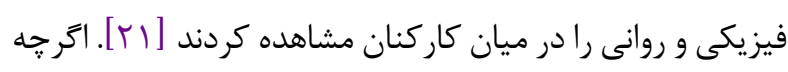

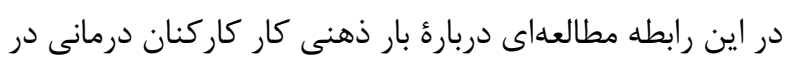

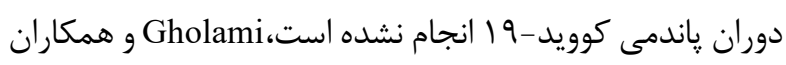

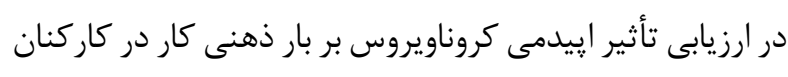

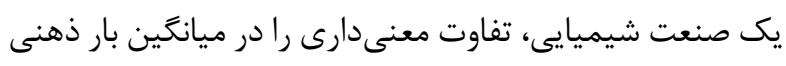

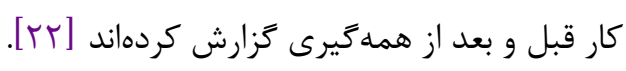

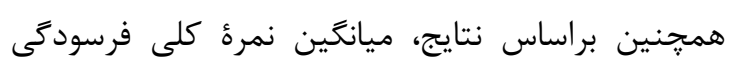

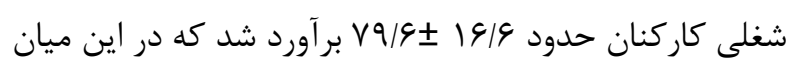

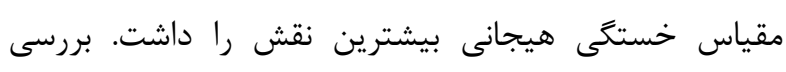

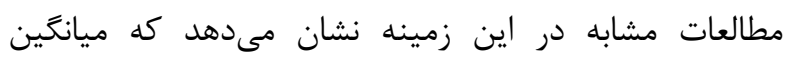

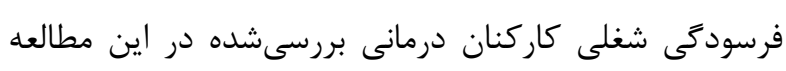

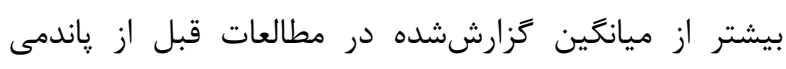

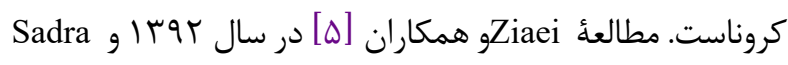

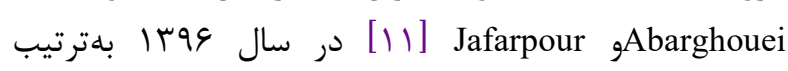

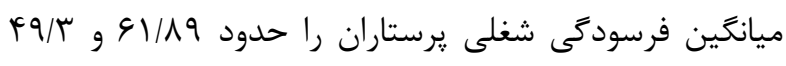


با بيماران مبتلا به كوويد-9 1، زنان و كاركنان متأهل تأثير بخذارد؛ بنابراين با توجه به نامشخصبودن زمان يايان اين همه بَّيرى،

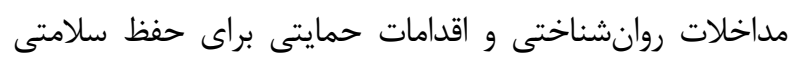
كاركنان طى دوران همه ميرى و بعد از آن ضرورى است.

$$
\text { تقدير و تشكر }
$$

اين مطالعه مستخرج از طرح يزوهشى با كد اخلاق IR.MUK.REC.1399.298 است كه بدينوسيله از حمايت مالى معاونت محترم تحقيقات و فناورى دانشگاه علوميزشكى

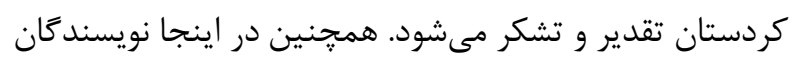
بر خود لازم مىدانند از يزشكان، يرستاران و ساير كادر درمانى

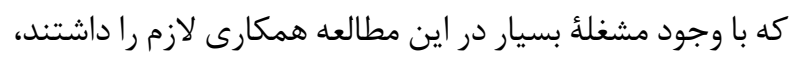
كمال تشكر و قدردانى را داشته باشند.

$$
\text { تعارض منافع }
$$

بين نويسندگان هيجزَنه تعارضى در منافع وجود ندارد.

$$
\text { منابع مالى }
$$

اين مقاله با مشاركت همةٔ نويسندگان تدوين شده و سهمم هر

$$
\text { نويسنده از كل مراحل انجام كار يكسان است. }
$$

\section{References}

1. WHO Coronavirus Disease (COVID-19) Dashboard: World Health Organization (WHO); 2020.Available from http://covid19.who.int.

2. Coronavirus disease (COVID-19) outbreak, Situation Report-86 WHO; 2020 [March 8]; Available from https://www.who.int/emergencies/diseases/novelcoronavirus-2019.

3. Zu ZY, Jiang MD, Xu PP, Chen W, Ni QQ, Lu GM, Zhang LJ. Coronavirus disease 2019 (COVID-19): a perspective from China. Radiology. 2020;296(2):E15-25. [DOI:10.1148/radiol.2020200490] [PMID] [PMCID]

4. The Islamic Republic of Iran Medical Council, 2021, https://irimc.org/en.

5. Ziaei M, Yarmohammadi H, Karamimatin B, Yarmohammadi S, Nazari Z, Gharagozlou F. Prevalence and risk factors of occupational burnout among nurses of a hospital in Kermanshah in 2013. Iran J Ergon. 2014;2(2):67-74.

6. Giahi O, Darvishi E, Akbarzade M. Assessment of the relationship of the risk of subjective work load to musculoskeletal disorders in bank staff in Kurdistan Province. Sci J Kurd Univ Med Sci. 2014;19(4): 36-45.

7. Taheri MR, Habibi E, Hasanzadeh A, Mahdavi Rad M. Relative Stress Index (RSI): Macro Ergonomics Risk
مختلف نيز از شدت بالاى فرسودىى در اين گروه شغلى در دوران

$$
\text { ياندمى حكايت دارد. }
$$

موضوع مهم ديخر اهميت سه شهر متفاوت و نتايج متفاوت

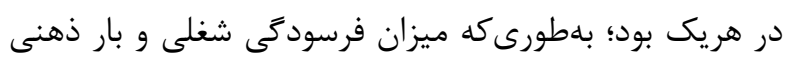

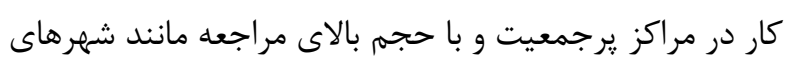

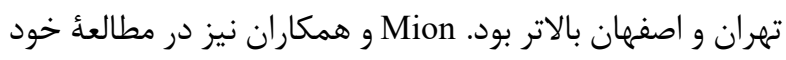

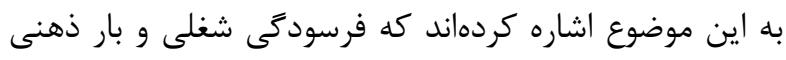
كار با جمعيت بيماران و حجم بالاى مراجعان در كاركنان مراكز

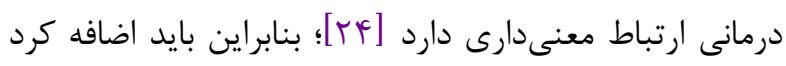
كه در زمان انجام اين مطالعه شرايط ابتلا در اصفهان و ديخر

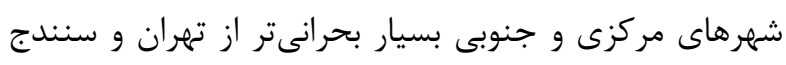
بود. در اجراى تحقيقات ميدانى محدوديتهاى خاصى وجود

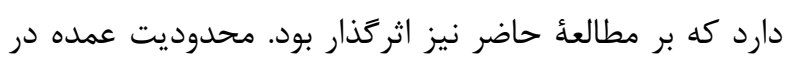
اين مطالعه مربوط به جمع آورى دادهها و همكارى كاركنان بودي؛

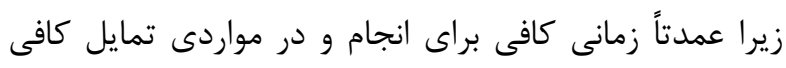
براى همكارى وجود نداشت.

$$
\begin{aligned}
& \text { نتيجه گَيرى } \\
& \text { همه گيرى كوويد-19 توانسته است بر ابعاد مختلف فيزيكى و } \\
& \text { روانى كارى كاركنان درمانى بلويزه كاركنان داراى ارتباط مستقيم كويد }
\end{aligned}
$$

Assessment of jobs in the textile industry. J Health Syst Res 2014; 10(4):25-35.

8. Bussières AE, Taylor J, Peterson C. Diagnostic imaging practice guidelines for musculoskeletal complaints in adults-an evidence-based approach-part 3: spinal disorders. J Manipulative Physiol Ther. 2008; 34: 366-72. [DOI:10.1016/i.jmpt.2007.11.003] [PMID]

9. Safari S, Mohammadi-Bolbanabad H, Kazemi M. Evaluation mental work load in nursing critical care unit with national aeronautics and space administration task load index (NASATLX). J Health Syst Res. 2013;9(6):613-9.

10. Bakhshi E, Mazlomi A, Hoseini SM. Mental workload and its determinants among nurses in one hospital in Kermanshah city, Iran J Occup Hyg Eng. 2017;3(4):5360. [DOI:10.21859/johe-03047]

11. Sadra Abarghouei N, Jafarpour H. Surveying the relationship of Total Ergonomics with burnout (With Case Study). Iran J Ergon. 2017;5(1):51-9. [DOI:10.21859/joe-05017]

12. West CP, Huschka MM, Novotny PJ, Sloan JA, Kolars JC, Habermann TM, Shanafelt TD. Association of perceived medical errors with resident distress and empathy: a prospective longitudinal study. Jama. 2006 Sep 6;296(9):1071-8.

[DOI:10.1001/jama.296.9.1071] [PMID] 
13. Saberi H, Moraveji A, Naseh J. Occupational burnout among school teachers and some related factors in Kashan 2007. ISMJ. 2011;14(1):41-50.

14. Massoudi R, Aetemadifar S, Afzali SM, Khayri F, Hassanpour Dehkordi A. The influential factors on burnout among nurses working in private hospitals in Tehran. Iran. J. Nurs. Res. 2008;3(9):47-58.

15. Cao A, Chintamani KK, Pandya AK, Ellis RD. NASA TLX: Software for assessing subjective mental workload. Behavior research methods. 2009;41(1):113-7. [DOI:10.3758/BRM.41.1.113] [PMID]

16. Talaei A, Mokhber N, Mohammad Nejad M, Samari AA. Burnout and its related factors in the staff of university hospitals in Mashhad in 2006. Journal of Semnan University of Medical Sciences. 2008;9(3):237-45.

17. Mirkamali K, Ahmadizad A, Kazemzadeh S, Varmaghani M. Determining the Relationship Between Job Burnout and Employee Productivity. Iran J Ergon. 2019 May 10;7(1):37-44. [DOI:10.30699/jergon.7.1.37]

18. Zakerian SA, Abbasinia M, Mohammadian F, Fathi A, Rahmani A, Ahmadnezhad I, Asghari M. The relationship between workload and quality of life among hospital staffs. J Ergon. 2013;1(1):43-56.

19. Sarsangi V, Saberi HR, Hannani M, Honarjoo F, SalimAbadi M, Goroohi M, Kazemi H. Mental workload and its affected factors among nurses in Kashan province during 2014. J Rafsanjan Univ Med Sci Health Serv. 2015;14(1):25-36.

20. Pourteimour S, Yaghmaei S, Babamohamadi H. The relationship between mental workload and job performance among Iranian nurses providing care to COVID-19 patients: A cross-sectional study. J Nurs Manag. 2021; 00:1-10. [DOI:10.1111/jonm.13305] [PMID] [PMCID]

21. Du M, Hu K. Frontline Health Care Workers' Mental Workload During the COVID-19 Pandemic: A CrossSectional Study. Asia Pac J Health. 2021;33(2-3):303-5. [DOI:10.1177/1010539521997257] [PMID]

22. Gholami A, Yarandi MS, Ghasemi M, Koozekonan AG, Soltanzadeh A. Effect of coronavirus epidemic on job stress and mental workload: A longitudinal study in a chemical industry. Iran Occup. Health. 2020:1-9.

23. Rodríguez-López, A.M. Rubio-Valdehita, S. DíazRamiro, E.M. Influence of the CoViD-19 Pandemic on Mental Workload and Burnout of Fashion Retailing Workers in Spain. Int J Environ Res Public Health. 2021, 18, 983. [DOI:10.3390/ijerph18030983] [PMID] [PMCID]

24. Mion G, Hamann P, Saleten M, Plaud B, Baillard C. Psychological impact of the COVID-19 pandemic and burnout severity in French residents: A national study. Eur J Psychiatry. 2021. [DOI:10.1016/j.ejpsy.2021.03.005] 